\title{
DIREITOS CIVIS E GOVERNO TRUMP: IMPRESSÕES SOBRE UM ANTAGONISMO'
}

\author{
Celly Cook Inatomi²
}

O objetivo deste trabalho é apreender a atmosfera de defesa de direitos civis nos Estados Unidos durante o primeiro ano do governo Donald Trump, de forma a verificar as concepções e os tipos de mobilização do direito sustentados por diferentes forças políticas e sociais. Para isso, a pesquisa analisou um total de 1 mil materiais extraídos de dois jornais de grande circulação no país, The New York Times e The Wall Street Journal, abrangendo notícias, editoriais, artigos de opinião, cartas de leitores, entrevistas, críticas culturais, seções especiais e até mesmo obituários. Os resultados obtidos mostraram uma forte polarização política. De um lado, os progressistas se uniram em torno de concepções de direitos civis já esperadas, abarcando a necessidade de políticas sociais e identitárias. Isolados politicamente, não conseguiram, naquele momento, avançar com propostas de expansão ou de criação de novos direitos, limitando-se apenas a negar ou se opor às políticas de Trump. Do outro lado, conservadores e liberais clássicos se uniram em uma espécie de "engenharia legal", casando o discurso liberal clássico com políticas e concepções conservadoras de direitos, atualizando de forma bastante retrógrada os significados dos direitos civis.

Palavras-chave: Estados Unidos; direitos civis; política de direitos; mobilização do direito.

\section{CIVIL RIGHTS AND THE TRUMP GOVERNMENT: IMPRESSIONS OF AN ANTAGONISM}

The aim of this article is to capture the atmosphere of civil rights advocacy in the United States during the first year of Donald Trump's rule, in order to verify the conceptions and types of mobilization of law supported by different political and social forces. To do so, the survey analyzed a total of one thousand materials extracted from two major newspapers in the country: The New York Times and the Wall Street Journal. The analysis covered daily news, editorials, open editorials, readers' letters, interviews, cultural critiques, special sections, and even obituaries. The results obtained showed strong political polarization. On the one hand, progressives have united around expected civil rights conceptions, embracing the need for social and identity politics. Politically isolated, they were unable to move forward with propositional policies of expansion or creation of new rights, just trying to deny or oppose Trump's policies. And on the other hand, conservatives and classical liberals came together in a kind of "legal engineering," marrying the classic liberal discourse with conservative rights-based policies and conceptions, updating in a rather retrograde way the civil rights meanings.

Keywords: United States; civil rights; politics of rights; mobilization of law.

1. Agradeço a Christian Camilo pela ajuda com leituras, revisões e debates sobre o tema desta pesquisa.

2. Pesquisadora colaboradora no Instituto Nacional de Ciência e Tecnologia para Estudos sobre os Estados Unidos (INCT-INEU). E-mail: <celoca05@yahoo.com.br>. 


\section{DERECHOS CIVILES Y EL GOBIERNO DE TRUMP: IMPRESIÓNES ACERCA DE UN ANTAGONISMO}

El propósito de este artículo es capturar la atmosfera de defensa de los derechos civiles en los Estados Unidos durante el primer año de la administración de Donald Trump, para verificar las concepciones y tipos de movilización de la ley apoyada por diferentes fuerzas políticas y sociales. Para esto, la investigación analizó un total de 1,000 materiales extraídos de dos periódicos de amplia circulación en el país, The New York Times y The Wall Street Journal, cubriendo noticias, editoriales, artículos de opinión, cartas de lectores, entrevistas, crítica cultural, secciones especiales y incluso obituarios. Los resultados obtenidos mostraron una fuerte polarización política. Por un lado, los progresistas unidos en concepciones ya esperadas de los derechos civiles, que abarca la necesidad de políticas sociales y minoritarias, no pudieron, en ese momento, presentar propuestas de expansión o creación de nuevos derechos, simplemente negando o oponiéndose a las políticas de Trump. Por otro lado, conservadores y liberales clásicos se han unido en una especie de "ingeniería legal" para alinear el discurso liberal clásico con políticas y concepciones de derechos conservadoras, haciendo una actualización bastante retrógrada de la concepción de los derechos civiles.

Palabras clave: Estados Unidos; derechos civiles; política de derechos; movilización del derecho. JEL: D7; D74.

\section{INTRODUÇÃO}

O que significa defender os direitos civis nos Estados Unidos de Donald Trump? Que fundamentos embasam essa defesa? São fundamentos de ordem puramente liberal, progressista ou, ainda, conservadora? Não soa estranho falar em defesa conservadora dos direitos civis? Soa estranho para quem tem como referência o movimento dos anos 1960. Contudo, é uma realidade que não podemos negar.

Quando olhamos para o primeiro ano do governo Trump, o cenário é de extrema polarização política e de acirrada disputa em torno do que deve ser o direito e de quais direitos devem ser válidos. De um lado, estão os progressistas, unidos em torno de concepçóes de direitos civis que abrangem a necessidade de políticas sociais e identitárias. Do outro, estão conservadores e liberais clássicos, unidos em uma verdadeira "engenharia legal", que casa o discurso liberal clássico com políticas e concepçôes conservadoras de direitos, reapropriando-se de fatos históricos e dos significados dos direitos civis.

Os resultados dessa disputa parecem ser dois. Primeiro, evidencia-se a derrota na capacidade de proposição das concepçôes progressistas de direitos civis, que se encontram, ao menos neste primeiro momento, politicamente isoladas. Embora sejam numericamente maiores, as açóes a seu favor são de caráter eminentemente defensivo, restringindo-se à defesa de direitos já conquistados e às tentativas de impedir que as novas diretrizes governamentais aprofundem discriminaçóes de minorias diversas. Segundo, os resultados nos mostram a face conservadora do direito liberal clássico, que, sob os auspícios da liberdade de expressão e da liberdade dos estados, tem legitimado a violaçẫo crescente de direitos civis. $\mathrm{O}$ resgate do que 
chamam de "verdadeiros" valores políticos americanos assim como a rediscussão da questão federalista no país querem fazer renascer, sob novas roupagens, a dita "identidade americana", como uma ofensiva às políticas de Barack Obama e ao que ele representou enquanto estadista. O slogan de campanha de Trump, Make America Great Again, não tem somente caráter publicitário e eleitoreiro, mas ajuda a revelar qual América, quais cidadáos e quais direitos se quer resgatar e defender.

Assistimos, assim, a um escarafunchar dos fundamentos dos direitos, com impactos concretos e diretos sobre a realidade política e jurídica dos Estados Unidos. Bobbio (1992), ao falar sobre direitos humanos, dizia que era inútil pensarmos em seus fundamentos, não porque eles estivessem apaziguados e livres de disputas, mas justamente por não ser possível pensar em fundamentos absolutos. Santos (2014), contudo, nos aponta que, ainda que não possa haver fundamentos absolutos, é urgente a discussão sobre eles, ao passo que os fundamentos estão sendo fortemente mobilizados, especialmente no campo filosófico e religioso, e com intuitos de se tornarem absolutos. Segundo o autor, algumas "não hegemonias" têm tentado, e com sucesso, substituir a hegemonia liberal clássica existente por uma outra hegemonia, desta vez mais conservadora e que faz uma combinação bastante peculiar e transnacional entre fundamentos conservadores (inclusive de caráter religioso) e liberdades clássicas.

Embora Santos (2014) esteja falando sobre direitos humanos e não especificamente sobre os direitos civis nos Estados Unidos, sua análise nos ajuda a pensar a influência interna dos fundamentos de caráter conservador, que, aliados a uma concepção liberal clássica de não interferência do Estado para políticas sociais, fazem os direitos civis de setores da população serem questionados ou interpretados a partir de chaves bastante peculiares. Parece, inclusive, que vivemos uma grande onda de retórica reacionária, tal qual descrita por Hirschman (1991), mas dessa vez com proporçóes tão gigantescas a ponto de ser possível pensar no fim da era dos direitos.

E como chegamos a esses resultados? Recorrendo, sobretudo, a meios teóricos e metodológicos que nos ajudaram na busca e na análise das diferentes concepçóes de direito em disputa no governo Trump. Para nosso auxílio teórico, fizemos uso seletivo da abordagem da mobilizaçáo do direito. De modo mais claro, usamos algumas tentativas iniciais de reformulação dessa abordagem. Resultante de diversas influências, a mobilização do direito tem em sua origem os estudos culturalistas e interpretativistas do direito, que, entre outras características, têm por objetivo compreender as concepções e as mobilizaçôes do direito "de baixo para cima". Isto é, trabalham com os entendimentos e os usos do direito de movimentos sociais e cidadãos individuais, para ver de que forma o ordenamento jurídico oficial pode ser constituído e/ou afetado por esses entendimentos diversos 
e vice-versa (Gordon, 1984; McCann, 1994; Silverstein, 1996; Brigham, 1997). Os trabalhos do Amherst Seminar (Seminário de Amherst) são os exemplos mais claros dessa conhecida "virada cultural", abrindo, sobretudo a partir dos anos 1980, uma ampla agenda de pesquisas para o estudo do direito in everyday life (na vida diária) (Sarat e Kearns, 1991; 1992; 1993).

A abordagem da mobilização do direito bebe bastante desses trabalhos culturalistas, e recebe por tabela as críticas que lhe são direcionadas. São geralmente apontados como trabalhos que, embora tenham possibilitado o avanço de pesquisas etnográficas e detalhistas sobre diferentes realidades e problemas, teriam perdido a capacidade de perceber o direito como um instrumento de dominação. Ao considerarem toda e qualquer manifestação vinda de baixo como detentora de um caráter construtor de novas concepções de direito, também passaram a entender essas manifestaçóes como capazes de concorrer, enganar ou substituir o chamado "direito oficial". Em outras palavras, teriam perdido a capacidade de trabalhar com grandes questóes teóricas, tais como a hegemonia do direito liberal e o direito como expressáo e instrumento de poder das classes dominantes (Hunt, 1990).

Embora a mobilização do direito não tenha essa preocupação como norte de pesquisa (McCann, 1996), a sua incapacidade de ver o direito como instrumento de controle tem se tornado claramente um problema para a abordagem nos dias de hoje, especialmente se quisermos estudar o cenário estadunidense a partir de 2017. Afinal, como não falar das grandes teses sobre o papel repressor e controlador do direito em um quadro de avanço do conservadorismo, de suas alianças com o direito liberal, bem como de emergência de teses anunciando o fim da era dos direitos?

Michael W. McCann, um dos expoentes centrais da mobilização do direito, vem há alguns anos reconhecendo essa incapacidade da abordagem, bem como a necessidade de sua transformação (McCann, 2006), e assim o faz não para que ela se torne estritamente positivista e cientificista, ou ainda produtora de grandes teorias - como requisitou Rosenberg (1996) -, mas para aprofundar e aperfeiçoar a ideia do caráter constitutivo do direito. Considerar esse caráter constitutivo do direito é de fato entender que no seu processo de construção ocorrem disputas entre diferentes concepçôes, que acabam constituindo umas às outras. Também implica entender, porém, que nessas disputas questôes como hegemonia, autoritarismo e conservadorismo podem derrotar qualquer pretensão menor de construção e validação social de significados. Com isso, é necessário compreender não apenas o que vem "de baixo" ou dos movimentos e organizações sociais progressistas, mas também o que vem "de cima" e dos contramovimentos e das organizaçóes conservadoras da própria sociedade civil. É nesta brecha que 
entra o nosso trabalho: este é um pontapé inicial na investigação de concepções de direito de ambos os espectros políticos, ao passo que a realidade não nos deixa ignorar o avanço de concepçóes autoritárias e conservadoras.

Para nosso auxílio metodológico, utilizamos um material empírico extraído de dois jornais de grande circulação nos Estados Unidos, The New York Times e The Wall Street Journal, ${ }^{3}$ coletando e analisando todo e qualquer documento que tenha feito referência aos direitos civis e ao direito como um todo durante 2017. Assim, catalogamos e analisamos cerca de 1 mil materiais, entre eles notícias, editoriais, artigos de opiniáo (ou open editorials), cartas do leitor, entrevistas, críticas (de cinema, livro, teatro, documentário etc.), seçôes especiais, transcriçôes de discursos e até mesmo obituários. ${ }^{4}$

Embora o leitor vá se deparar mais adiante com alguns gráficos, eles não têm por objetivo comprovar ou negar teorias. Eles nos auxiliam no processo de organização e condensação de informaçôes básicas para a extração dos significados que os materiais empíricos nos permitiram extrair. Os gráficos nos ajudam a visualizar as intensidades com que as diferentes concepçôes sobre o direito aparecem e se relacionam entre si. E, talvez mais importante, eles nos ajudam a visualizar as convergências entre atores e entre concepçóes, convergências essas responsáveis pela crise dos direitos civis nos Estados Unidos de hoje.

\section{OS FUNDAMENTOS DOS DIREITOS CIVIS NAS DISPUTAS ENTRE OS ATORES}

Nos Estados Unidos de 2017, sob um forte clima de polarização política, dois grandes grupos disputam o significado dos direitos civis. De um lado, está o setor de oposição ao governo Trump, formado por uma variedade de atores políticos e sociais, tais como: organizaçóes de direitos civis, parlamentares democratas, movimentos de mulheres, movimento de lésbicas, gays, bissexuais, travestis, transexuais ou transgêneros (LGBTs), movimentos negros, cidades-santuário, professores universitários, artistas, atletas e alguns estados federativos. Do outro lado, está o setor de apoio ao governo Trump, formado por elites políticas e também por uma variedade de atores políticos e sociais, tais como: membros da nova equipe governamental - principalmente o secretário do Departamento de Justiça (Jeff Sessions), a secretária do Departamento de Educação (Betsy DeVos), o assessor Steve Bannon e o novo juiz da Suprema Corte, Neil Gorsuch -, membros

3. 0 objetivo não é verificar o posicionamento de cada jornal e estruturar o estudo em torno disso. Os jornais foram escolhidos por se saber previamente que apresentam posicionamentos políticos distintos, o que ficará claro na citação dos materiais a cada vez que falarmos das visões progressistas e conservadoras e liberais clássicas de direitos. 4. As buscas foram feitas por meio da base de dados ProQuest da Universidade Estadual de Campinas (Unicamp), entre 12 de julho de 2017 e 9 de setembro de 2018. Para nos ajudar a trabalhar qualitativamente com essa grande quantidade de material escrito, utilizamos alguns instrumentos do software Atlas.TI, que auxiliou no processo de leitura, codificação e extração de significados do material lido. 0 Excel ajudou na tarefa de produção de gráficos dos códigos e dos significados obtidos com o Atlas. TI. 
do Departamento de Saúde e Serviços Humanos e do Departamento de Segurança Interna, parlamentares republicanos, think tanks liberais e conservadores, policiais, alguns estados federativos, organizaçóes religiosas e conservadoras, supremacistas brancos, membros da Ku Klux Klan e grupos neonazistas.

No lado da oposição ao governo, os fundamentos para a defesa dos direitos civis são eminentemente de ordem liberal progressista. Isso significa que os opositores veem os direitos civis a partir da ótica dos movimentos dos anos 1960, do Estado de bem-estar social, e dos direitos identitários, pensando as relaçóes de discriminação, exclusão e desigualdade. Com frequência, mobilizam diversas das leis dos direitos civis (Civil Rights Act) promulgadas durante os anos 1960, decisões progressistas e históricas da Suprema Corte, políticas identitárias do governo Obama, além de valores como equidade, diversidade, tolerância religiosa, direitos humanos e princípios democráticos de governo.

No lado de apoio a Trump, por seu turno, os fundamentos para a defesa dos direitos civis são de três ordens: uma primeira, liberal clássica, uma segunda, conservadora, e uma terceira, extremista, defensora de valores racistas. Isso significa que os apoiadores de Trump veem (ou podem ver) os direitos civis a partir de três óticas distintas. Primeiramente, a partir da ótica do liberalismo clássico, mobilizando conceitos como a liberdade de expressão, de opiniáo e de discurso, a liberdade religiosa, a liberdade de mercado e de escolha, a meritocracia, a filantropia, o devido processo legal e, sobretudo, a liberdade dos estados. Em segundo lugar, a partir da ótica do conservadorismo, mobilizando valores religiosos cristãos, a moralidade, a valorização da vida e da família tradicional, a caridade, a não interferência do Estado na educação das crianças, a segurança pública contra a criminalidade e as drogas, o patriotismo e a segurança nacional contra ataques terroristas. E, em terceiro lugar, também podem ver os direitos civis a partir da ótica do extremismo, mobilizando sentimentos nacionalistas étnicos e de superioridade racial.

Essas diferentes óticas sobre os direitos civis podem ser observadas em detalhes principalmente nas disputas que os opositores e apoiadores de Trump travam pelas políticas de direitos. Mais importante é que somente no momento dessas disputas, com a exposiçáo dos fundamentos de cada ator, conseguimos ver que os apoiadores conservadores e até extremistas de Trump se fortalecem pela mobilização de argumentos com raiz na ótica liberal clássica - uma vez que os extremistas fazem um uso estratégico e seletivo de tal ótica, em consonância com os seus propósitos -, especialmente por meio da utilização das liberdades da Primeira Emenda da Constituição e da liberdade dos estados. Como veremos, os fundamentos liberais clássicos são usados com frequência como uma retórica ou uma roupagem para que políticas draconianas de cortes de direitos sejam implementadas, isso quando esses fundamentos não são reinterpretados por 
completo dentro de uma lógica eminentemente conservadora, com consequências ainda mais nocivas para os direitos civis.

\subsection{Liberais progressistas e o movimento dos direitos civis dos anos 1960, segunda parte}

Tem se falado, entre artistas, intelectuais e ativistas liberais progressistas e até radicais, na existência de um segundo movimento por direitos civis, muito semelhante ao que teria ocorrido durante os anos $1960 .^{5}$ Tal semelhança se dá, sobretudo, pela manutençáo e pelo aumento do racismo como uma espécie de norma não escrita que teima em continuar regendo as relaçóes sociais e políticas norte-americanas; ${ }^{6}$ sem falar na manutenção de diversos outros problemas que o racismo corta de forma transversal, como a violência policial, as políticas estaduais de supressão de votos e uma diversidade de outras políticas para a educação e para a habitação, por exemplo. Além do racismo, também se fala na manutenção e no aumento de uma série de outras discriminaçôes, como aquelas contra as mulheres e LGBTs, que também foram temas presentes nos movimentos por direitos civis do passado. Ademais, fala-se claramente no atual problema da xenofobia, que surge como um tema contemporâneo entre os mais importantes.

Embora tenha acabado a era Jim Crow, período de forte segregação racial nos Estados Unidos, e embora leis de proteção à igualdade e contra discriminações diversas tenham sido promulgadas, essas garantias estão sendo concreta e crescentemente ameaçadas. Para o grande setor liberal progressista, a eleição de Trump representou o selamento institucional ou a reidratação de um passado norte-americano sombrio de segregação e discriminação. Diversas são as manifestaçóes que veem em Trump a personificação da América racista e discriminatória, ${ }^{7}$ falando de seus apoiadores entre supremacistas brancos ${ }^{8}$ e das ligaçôes entre as suas falas e os crimes de ódio cometidos por grupos extremistas (Ballhaus e Reinhard, 2017; Stolberg e Rosenthal, 2017; Thrush, 2017; Black,

5. Ver, por exemplo, o trabalho do artista plástico Kerry James Marshall, que procura retratar a necessidade da representatividade negra, resgatando a sua memória bem como o movimento negro por direitos civis dos anos 1960. Segundo o artista, vivemos com toda certeza um segundo movimento por direitos civis, e sua arte seria uma expressão disso. Sua obra se manteve presente na agenda cultural de Nova lorque em janeiro de 2017, sendo reportada constantemente pelo The New York Times em seus schedules culturais. Para mais informações, ver Museums... (2017) e Cotter (2017b). Também encontramos manifestações artísticas explícitas falando sobre um segundo movimento de direitos civis em obras expostas no Charles H. Wright Museum of African American History, que retratam a atuação do Black Lives Matter para mostrar como o passado está se repetindo. Mais informações em Luongo (2017).

6. Claramente, dentro do grande tema racismo, aparecem materiais que resgatam a história da escravidão e a era Jim Crow. Contudo, por mais que não estejam fazendo referência ao agora, estão resgatando o passado para analisar o presente, de forma a apontar a ainda existente segregação racial no país, mas que se dá por diferentes formas em relação ao passado.

7. Mais informações em Shear e Alcindor (2017), Dyson (2017), Badger (2017a; 2017b), Leland (2017), Anderson (2017), Burch (2017), Brantley, Green e Soloski (2017), Black (2017), Alcindor (2017c), Fearing... (2017) e Krugman (2017a).

8. Para mais informações, ver Eligon, Blinder e Najar (2017), Stack (2017), Blinder, Kovaleski e Goldman (2017), Dewan e Williams (2017), Trump... (2017) e Ballhaus e Reinhard (2017). 
2017). Chegam, inclusive, a caracterizá-lo como líder de um White Civil Rights Movement que subverte valores democráticos mínimos de convivência política e social, conquistados sobretudo com as lutas por direitos civis durante os anos 1960 (Zinoman, 2017; Bennet et al., 2017d; Winkler, 2017). Embora admitam que as medidas de Obama não tenham sido capazes de impedir os casos de racismo no país, especialmente na atuação policial, apontam que Trump representa o fim das poucas medidas existentes.

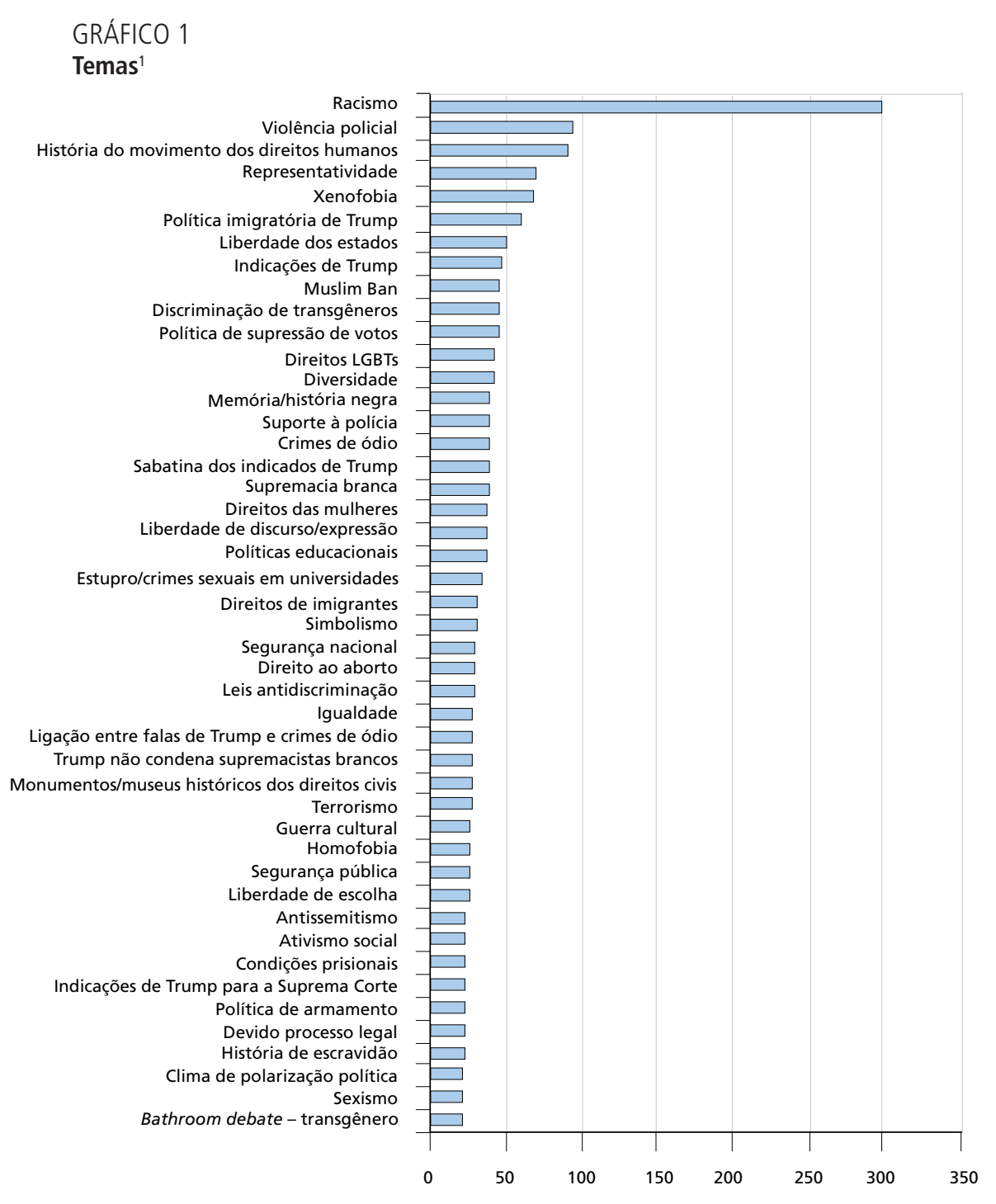

Elaboração da autora.

Nota: ${ }^{1}$ Por número de vezes que aparecem nos jornais analisados. 
As posturas discriminatórias do governo também são vistas na falta de compostura de Trump para ocupar o cargo de presidente da República, tomando-o como um "presidente hobbesiano" (Stephens, 2017). Comentam sobre seus ataques constantes a instituiçóes centrais à democracia, como a imprensa tradicional, chamando-a de mentirosa e "inimiga" da nação (Riley, 2017). Falam também sobre os tuítes sempre polêmicos e extremamente agressivos de Trump, ${ }^{9}$ que "governa" seu eleitorado incitando um interminável clima de campanha política e de divisão entre nós e eles ou entre amigos e inimigos. John Lewis, famoso líder do movimento dos direitos dos anos 1960, e membro democrata da Câmara dos Representantes, foi um dos inúmeros alvos de ataque de Trump na internet, e isso se deu náo apenas pelo fato de o parlamentar dizer que boicotaria o evento de posse de Trump, mas pelas razóes que ele apresentou para isso. Segundo Lewis, Trump não poderia ser considerado um presidente legítimo, não só em função de seus posicionamentos racistas, machistas, homofóbicos e xenófobos, mas principalmente por conta do envolvimento da Rússia nas eleições que o levaram à presidência do país (Landler, 2017).

A existência de um segundo momento na luta por direitos civis dos anos 1960 também pode ser vista na intensa mobilização do setor liberal progressista, que se utiliza, sobretudo, de açóes judiciais, expressóes culturais e protestos para tratar das políticas de cunho discriminatório do governo Trump. Entre os progressistas (de azul mais escuro no gráfico 2), os atores mais atuantes são organizaçôes de direitos civis, parlamentares democratas e movimentos de mulheres e artistas, ${ }^{10}$ ressaltando que as organizaçóes de direitos civis costumam tomar para si a defesa de diversos grupos e movimentos, como é o caso do movimento negro e do movimento LGBT. ${ }^{11}$

\footnotetext{
9. Mais informações em Shear, Fandos e Steinhauer (2017), Landler (2017), Savage e Lichtblau (2017), Thrush e Haberman (2017).

10. Os artistas aparecem em menor número aqui, apesar do alto número de mobilizações artísticas, porque o gráfico 2 , especificamente, fala sobre as relações de conflito que um ator ou atores estabelecem com outros de forma clara ou anunciada. Os artistas, em sua grande maioria, não conflitam necessariamente com uma pessoa ou um grupo de pessoas, mas brigam com ideias e concepções, geralmente expressando mais contrariedade a estas do que a seus propagadores. Embora saibamos os atores que eles estão criticando, procuramos não falar pelos artistas a não ser que isso seja manifestado de forma expressa.

11. É por essa razão que esses atores específicos aparecem em número muito menor no gráfico 2, pois grande parte das suas manifestações está incorporada nas diversas organizações de direitos civis. Quando registramos no gráfico em questão conflitos entre LGBTs e negros contra o governo, estamos fazendo referência a conflitos particulares de pessoas desses grupos que entraram na justiça, por exemplo, sem o apoio de instituições, movimentos ou organizações maiores.
} 


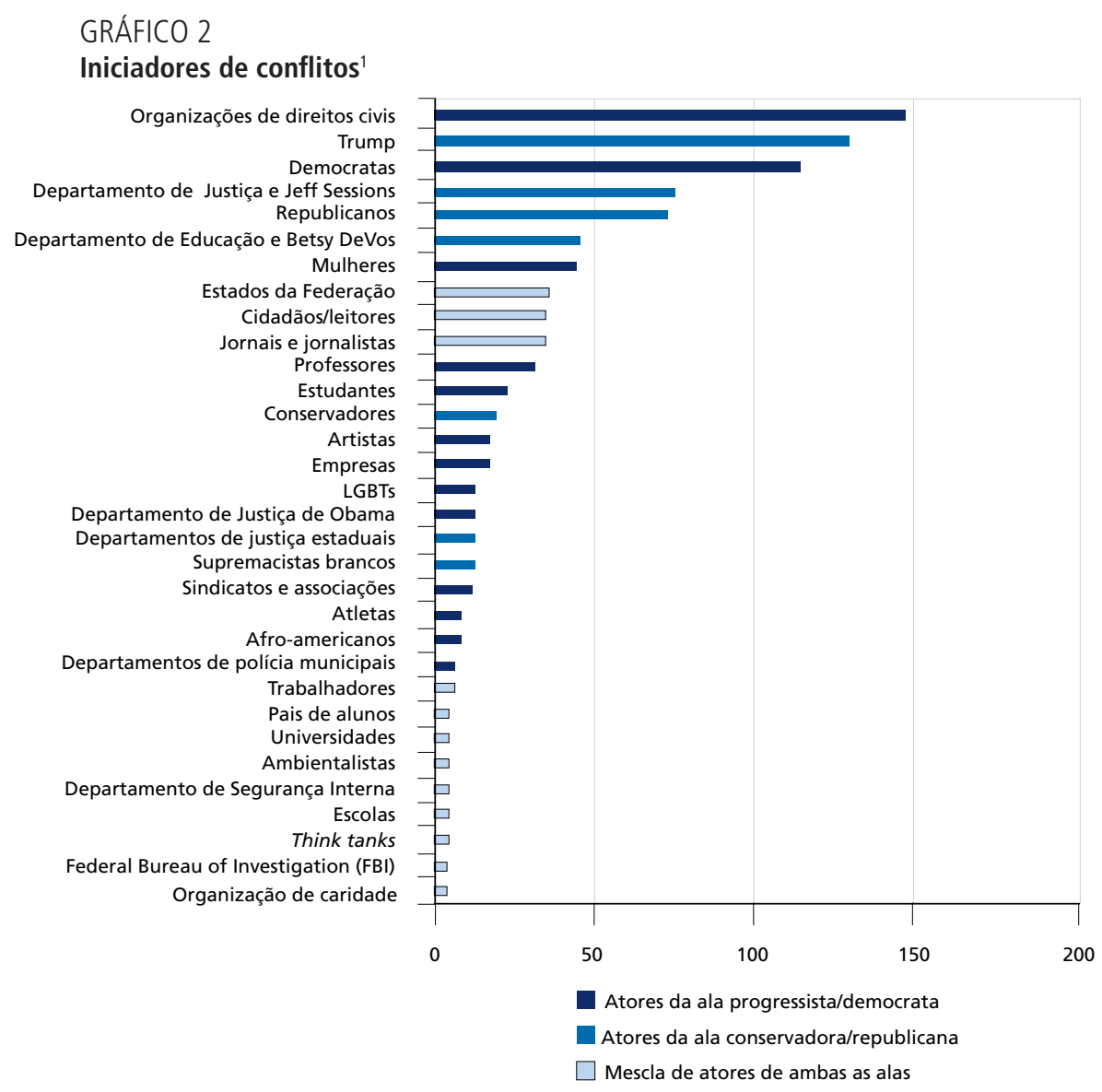

Elaboração da autora.

Nota: ${ }^{1}$ Por número de vezes que aparecem nos jornais analisados.

Esses atores se envolvem em uma miríade de conflitos pela política de direitos, começando pela questão do racismo e da violência policial. Nesta seara, eles têm feito forte oposição a Trump e ao seu Departamento de Justiça (na figura de Jeff Sessions) em função de suas tentativas de reverter as já frágeis políticas de Obama para a diminuição e inibição do racismo institucional da polícia. Obama havia se utilizado bastante dos decretos de consentimento (consent decrees),${ }^{12}$ uma espécie de federalização da administração dos departamentos de polícia locais, de forma que o Departamento de Justiça tivesse como "policiar as polícias" para que elas cumprissem com as leis federais de não discriminação e de uso diligente 
da força policial. Os departamentos de polícia locais eram então obrigados a aplicar puniçóes disciplinares aos policiais acusados, sem que necessariamente eles tivessem passado por um processo judicial criminal que comprovasse a sua culpa. Além disso, os departamentos locais também eram obrigados a realizar cursos de reciclagem e treinamento de seus quadros. Essa política descontentou diversos departamentos de polícia locais, bem como sindicatos de policiais, republicanos, e uma série de cidadãos que saíram em defesa das polícias, e que viam em Trump e em seu novo Departamento de Justiça uma chance real de reversão dessa medida.

GRÁFICO 3

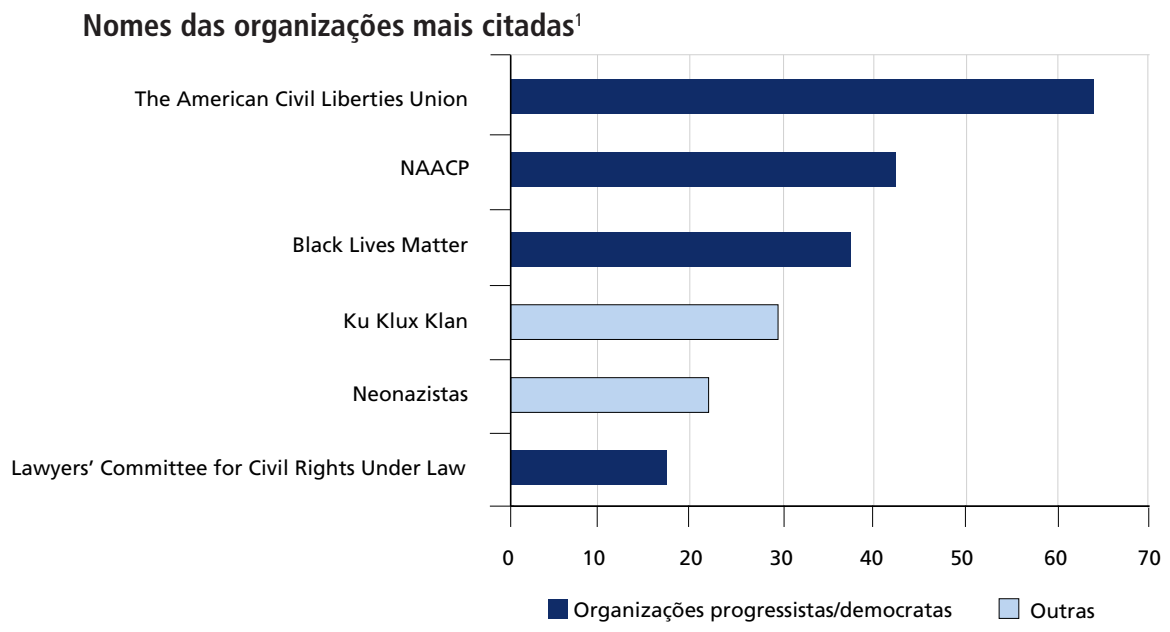

Elaboração da autora.

Nota: ${ }^{1}$ Por número de vezes que aparecem nos jornais analisados.

Obs.: NAACP - National Association for the Advancement of Colored People.

As organizaçóes de direitos civis, bem como movimentos negros, saíram em defesa dessas medidas de Obama, ainda que fossem frágeis, porque apontavam que elas constituíam algum tipo de solução para o problema do racismo policial, dado que, embora houvesse uma enxurrada de processos na Justiça, a sua efetividade era considerada baixa. Tanto é assim que o próprio movimento Black Lives Matter nasceu em 2013 como resposta à absolvição judicial de um policial que matou a tiros Trayvon Martin, um jovem negro de apenas 17 anos. Desde entáo, os movimentos negros iniciaram uma série de protestos, marchas nas ruas e movimentos artísticos, que se acirraram depois da eleição de Trump e de suas tentativas de dar apoio incondicional aos policiais. Durante os protestos e discursos públicos, lembram os inúmeros casos de racismo policial ${ }^{13}$ - inclusive

13. Lembram o caso de Rodney King: Badger (2017a), Rodríguez e Martínez (2017), Egner (2017) e Stolberg (2017c); e de Eric Garner, Sandra Bland, Tamir Rice, Michael Brown, entre outros: Southall (2017), Julie (2017), Feuer (2017), Baker e Mueller (2017), Stolberg (2017d), Ruiz e Apuzzo (2017), Bennet et al. (2017c), Alcindor (2017b) e Luongo (2017). 
o de Emmett Till, que deu ensejo aos movimentos por direitos civis nos anos $1960-{ }^{14}$ e também resgatam a memória de Martin Luther King, personalidade mais mobilizada entre os nossos materiais.

GRÁFICO 4

\section{Incidência de racismo segundo temas ${ }^{1}$}

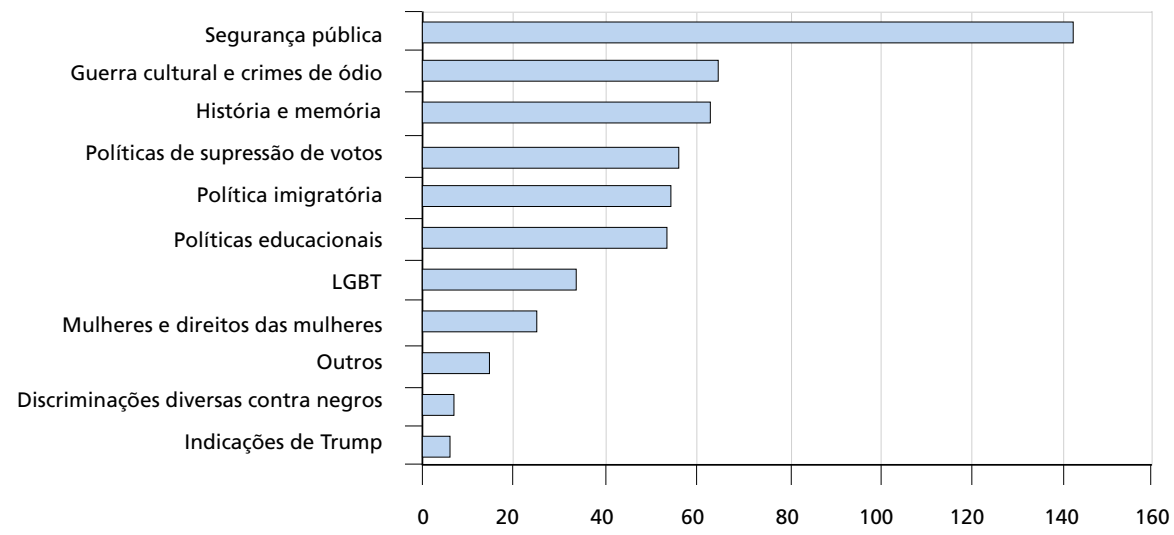

Elaboração da autora.

Nota: ${ }^{1}$ Por número de vezes que aparecem nos jornais analisados.

Junto com esses movimentos, deram-se açóes judiciais de organizaçóes de direitos civis, para questionar os departamentos de polícia que não estavam cumprindo com os decretos de consentimento firmados no governo anterior e que ignoravam as leis federais de não discriminação. No Congresso, parlamentares democratas questionaram as tentativas de Trump de reverter as políticas de Obama para disciplinar as polícias, tentando, desde o início do governo, barrar a nomeação de Jeff Sessions para o Departamento de Justiça, alegando seus posicionamentos racistas e suspeitos para ocupar um cargo tão importante e que lida táo diretamente com a proteção dos direitos civis (Savage e Lichtblau, 2017; Shear, 2017; Hulse, 2017b).

Ainda dentro do tema do racismo, outra disputa em que os liberais progressistas se envolvem é no campo das políticas estaduais de supressão de votos. Alguns estados, como o Texas, têm aplicado leis estaduais de exclusão de pessoas do registro eleitoral, principalmente em função de condenaçôes criminais anteriores. Segundo as organizaçóes de direitos civis e parlamentares democratas, essas medidas estariam permitindo uma verdadeira supressão de votos da população negra e da de descendência hispânica, que são as mais afetadas pela pobreza, pela desigualdade, e as mais propensas a serem criminalizadas. 
Com isso, denunciam que está ocorrendo uma verdadeira violação dos direitos políticos da população negra, conquistados, sobretudo, pelas mobilizaçôes por direitos civis durante os anos 1960 com a promulgação do Voting Rights Act de 1965 , e enquadram essa violação não apenas como racista, mas também como estratégia eleitoral assumida de republicanos para evitar os votos dessa população em candidatos democratas (Berman, 2017; Savage, 2017b; Bennet et al., 2017d; Fernandez, 2017). Assim como nos casos de violência policial, as organizaçóes de direitos civis têm questionado esses estados na justiça, além de fazer críticas públicas e no Congresso ao posicionamento de Trump e de Jeff Sessions como favoráveis a tais políticas em nome da liberdade dos estados e da não interferência do governo federal.

GRÁFICO 5

Legislações e políticas citadas para falar de racismo'

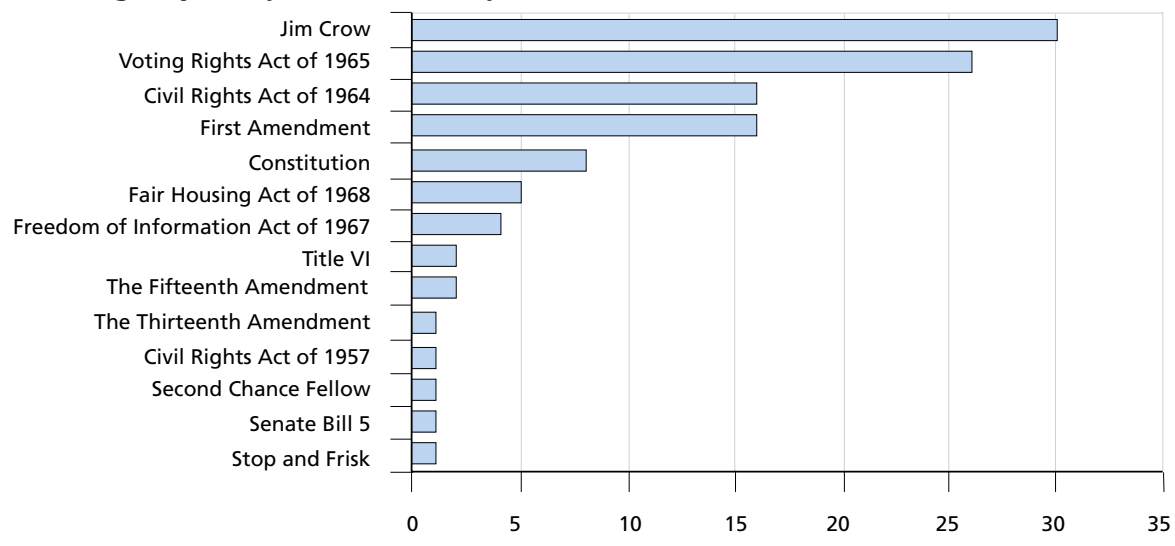

Elaboração da autora.

Nota: ${ }^{1}$ Por número de vezes que aparecem nos jornais analisados.

Outra disputa travada pelos liberais progressistas ocorre no cenário das liberdades de expressão e de opinião dentro das universidades. Algumas dessas organizaçóes progressistas, bem como professores, estudantes e o movimento negro, têm denunciado uma utilização arbitrária e invertida da liberdade de expressão, ao passo que ela tem sido cada vez mais mobilizada, como mostrou MacKinnon (2018), para propagar normas racistas e discriminatórias de convivência social. ${ }^{15}$ Obama havia implementado medidas, com base nas leis federais de não discriminação, para inibir os discursos racistas e de ódio nas universidades, estabelecendo sanções, inclusive orçamentárias, para aquelas que não punissem devidamente tais discursos. Diversos foram os casos, inclusive, de

15. Mais informações podem ser encontradas em Fortin (2017), Grimes (2017), Hartocollis (2017), Green (2017b), Stolberg (2017e) e Newman e Wang (2017). 
críticas aos estudantes e professores que tentaram impedir a realização de palestras de supremacistas brancos (Violence..., 2017; Parini e Callanan, 2017; Sartwell, 2017; Berkowitz, 2017; Donald, 2017b).

Nesse campo, os conflitos dos progressistas com o governo Trump se dão, sobretudo, em funçáo da sua intenção declarada de tomar a educação como uma das pautas centrais do que ele chama de movimentos por direitos civis dessa geração (Mann, 2017). Isso significa uma retomada dos valores liberais clássicos de liberdade de expressão, de opinião e de pensamento, para recuperar o que ele chama de "verdadeiro" papel da educação na criação de homens livres. Os atritos se acirram quando Trump indica Betsy DeVos para ocupar o cargo de secretária do Departamento de Educação, pois, pareada com o posicionamento de Trump sobre as políticas educacionais, ela também vai se voltar para a reversão das medidas implementadas por Obama, mas com o acréscimo de um pensamento religioso para a educaçáo, que coloca em xeque toda a defesa feita em torno de uma educação livre de ideologias e de ativismo político.

Ainda no campo da liberdade expressão, e envolvendo casos de racismo, também aparecem com expressividade as disputas em torno dos monumentos históricos em homenagem aos confederados. Neste campo, é possível perceber que existe uma verdadeira guerra cultural entre progressistas e conservadores, com alguns liberais clássicos no meio-termo. Movimentos negros e organizaçōes de direitos civis apelam para que as administrações municipais retirem monumentos confederados em função da memória racista que eles perpetuam na sociedade americana. ${ }^{16}$

\section{GRÁFICO 6}

\section{Cinco movimentos ou eventos históricos mais citados ${ }^{1}$}

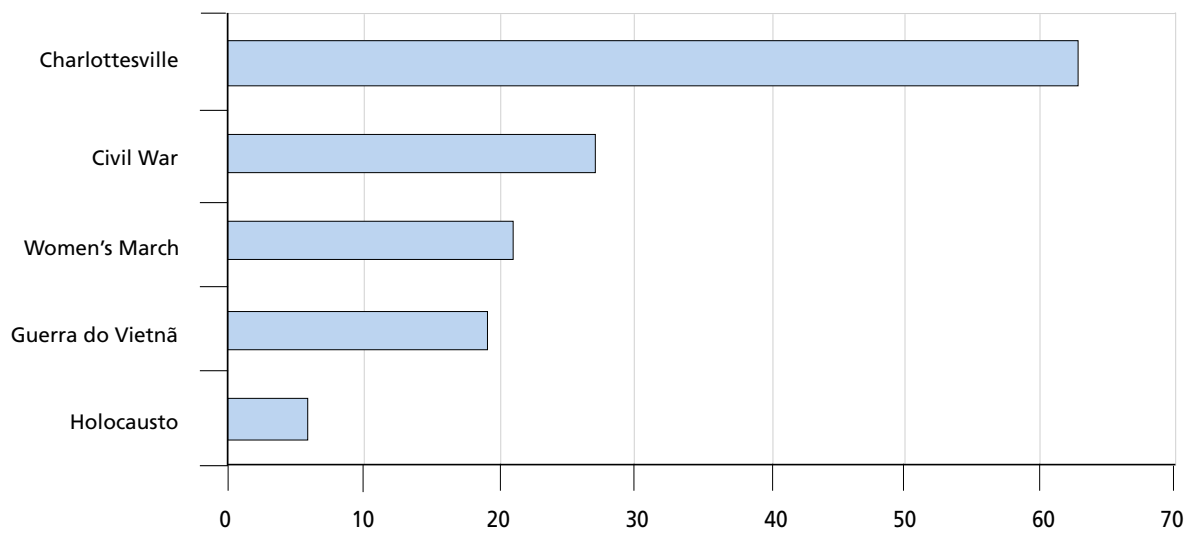

Elaboração da autora.

Nota: ${ }^{1}$ Por número de vezes que aparecem nos jornais analisados.

16. Mais informações em Cox (2017), Schuessler (2017), Katz (2017), Fandos, Fausset e Blinder (2017), Fausset (2017), Cotter (2017c), Paulson (2017), Romero (2017) e McWhirter (2017). 
Após o polêmico e assustador episódio de Charlottesville em agosto de 2017, esses movimentos e organizaçóes fortaleceram ainda mais seu posicionamento, apontando os crimes de ódio como consequência dessa memória que é constantemente nutrida e cuja manutenção é permitida justamente por conta do uso enviesado das liberdades clássicas de expressão, de opinião e de protesto. Eles apontam que o racismo não deveria ser protegido dentro dessas liberdades, ${ }^{17}$ uma vez que conclama a sociedade para normas segregacionistas de convivência, indo contra o próprio ideal de democracia e de liberdade americana. Apontam ainda que a insistência em situar os discursos racistas e de ódio dentro da alçada da liberdade de expressão mostra apenas que esta é e sempre foi uma liberdade apenas para brancos. Citam, inclusive, casos atuais em que artistas negros foram impedidos de expor suas obras de arte porque expunham policiais como praticantes de racismo institucional (Steinhauer, 2017).

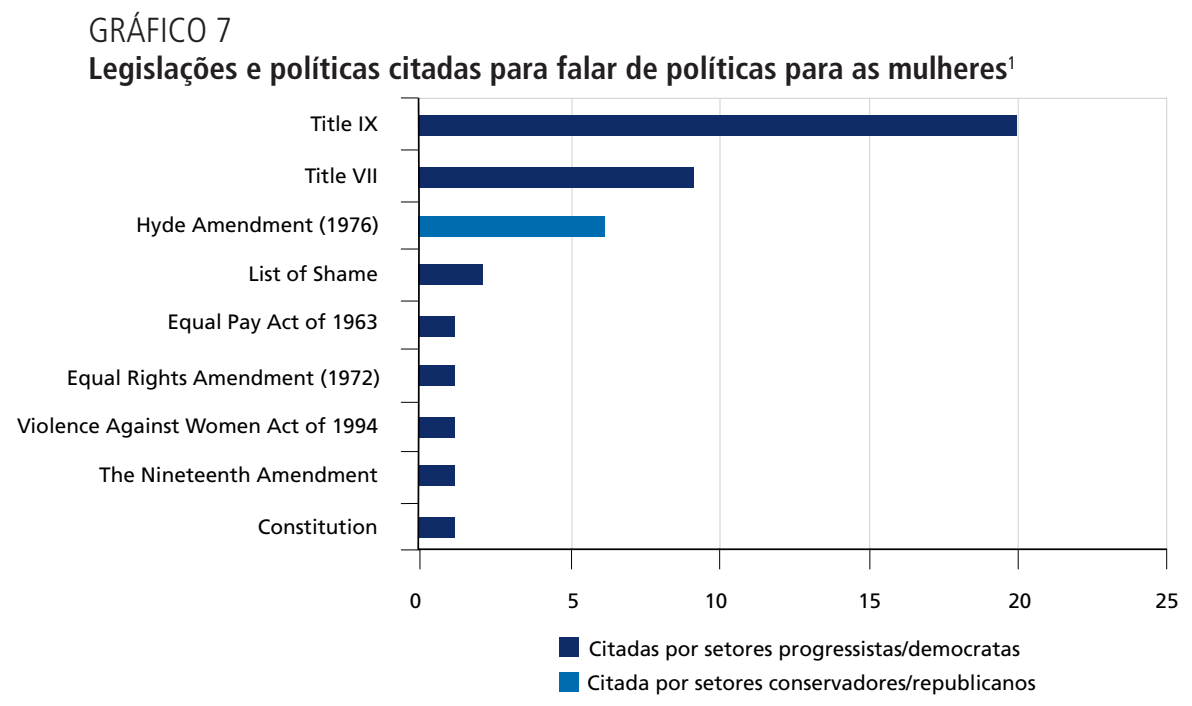

Elaboração da autora.

Nota: ${ }^{1}$ Por número de vezes que aparecem nos jornais analisados.

Outro conflito em que os liberais progressistas se envolvem gira em torno dos crimes sexuais cometidos contra as mulheres dentro de universidades. Obama havia implementado, também com base em leis federais de não discriminação (sobretudo o Title IX da Education Amendments of 1972), medidas que visavam impedir os crimes sexuais, entre elas sançóes orçamentárias para as universidades que não investigassem e nem punissem devidamente os estudantes acusados de estupro; além da criação do que ficou conhecido como List of Shame, em que os estudantes acusados eram expostos

17. Mais informações em Stolberg (2017g), The Open... (2017), Grynbaum (2017) e Fuller, Feuer e Kovaleski (2017). 
para evitar que outras mulheres fossem atingidas (Green e Stolberg, 2017). Segundo os materiais analisados, as organizaçóes de direitos civis, bem como os movimentos de mulheres, apontam que Trump e seu governo, sobretudo o Departamento de Educação, tratam esses casos não com base em quem sofre as violências, no caso, as mulheres, mas em quem pratica as violaçóes, os homens, invocando, principalmente, o direito do devido processo legal. ${ }^{18} \mathrm{Com}$ isso, os setores progressistas defensores dos direitos das mulheres mobilizam-se judicialmente e com falas críticas públicas contra o governo e sua "cruzada" no setor educacional.

GRÁFICO 8

Legislações e políticas citadas para falar de políticas LGBTs ${ }^{1}$

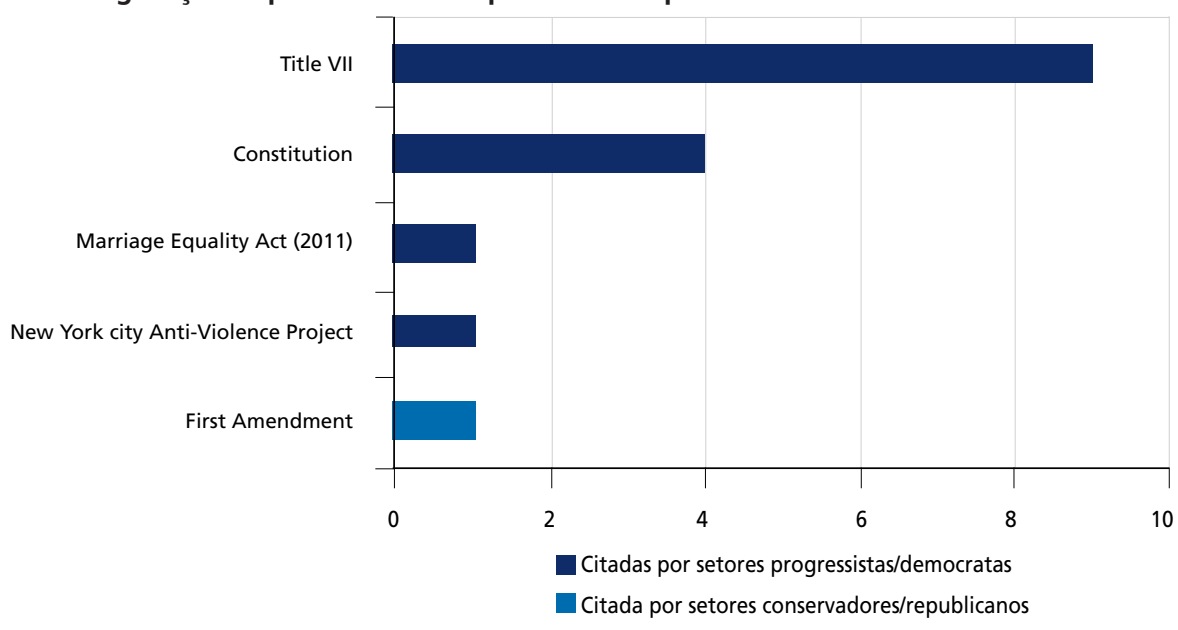

Elaboração da autora.

Nota: ${ }^{1}$ Por número de vezes que aparecem nos jornais analisados.

Outro conflito estabelecido por essas organizaçóes, relacionado a movimentos LGBTs, refere-se ao que ficou conhecido por debate do banheiro (bathroom debate), em que estados e governos locais têm impedido que alunos transgêneros utilizem o banheiro escolar de acordo com o gênero com o qual se identificam. Diversos desses casos foram parar na justiça, movidos, sobretudo, pelas organizaçóes de direitos civis, que alegam o náo cumprimento de leis federais contra a discriminaçáo (como é o caso do Title VII da Education Amendments of 1972). Além das ações judiciais, as organizaçóes, assim como o movimento LGBT, promoveram passeatas e protestos em frente às escolas relutantes em seguir leis de não discriminaçấo (Baylor's..., 2017; Green, 2017a). Neste caso, os liberais progressistas se voltam não somente contra as escolas, mas também contra Trump e seu Departamento de Justiça por quererem novamente reverter políticas de Obama em nome da liberdade dos estados e das localidades.

18. Mais informações em Stolberg (2017f), Ruiz (2017), Young (2017), Krakauer e Dunn (2017), Korn (2017), Silverglate (2017) e Taylor Junior (2017). 
Por fim, outro campo em que as organizações de direitos civis estabelecem conflitos é o das políticas imigratórias de Trump, especialmente no caso do Muslim Ban. Apontam que mais uma vez o presidente faz uma defesa arbitrária da liberdade dos estados, dado que ele os vê como submissos quando seguem regras anteriores de Obama, mas como livres quando seguem regras do seu governo. ${ }^{19}$ As organizações de direitos civis e outros atores progressistas tomam fundamentos mais abstratos para a defesa dos imigrantes, baseando-se geralmente nos direitos humanos, em valores de dignidade, de tolerância e também de opinião e de oposição política, tendo em vista os questionários de caráter político-ideológico para imigrantes conseguirem entrar no país. ${ }^{20}$ Algumas organizaçóes, aliadas a grandes empresas de tecnologia, manifestam-se de modo mais específico, alegando que as táticas de "caça" aos imigrantes ilegais, como políticas extremas de vigilância pública e de vigilância na internet, bem como sistemas de reconhecimento facial pela polícia, violam direitos de privacidade do próprio povo americano, não devendo, portanto, ser utilizadas (Savage, 2017c; Meckler, 2017).

GRÁFICO 9

\section{Legislações e políticas citadas para falar de política imigratória'}

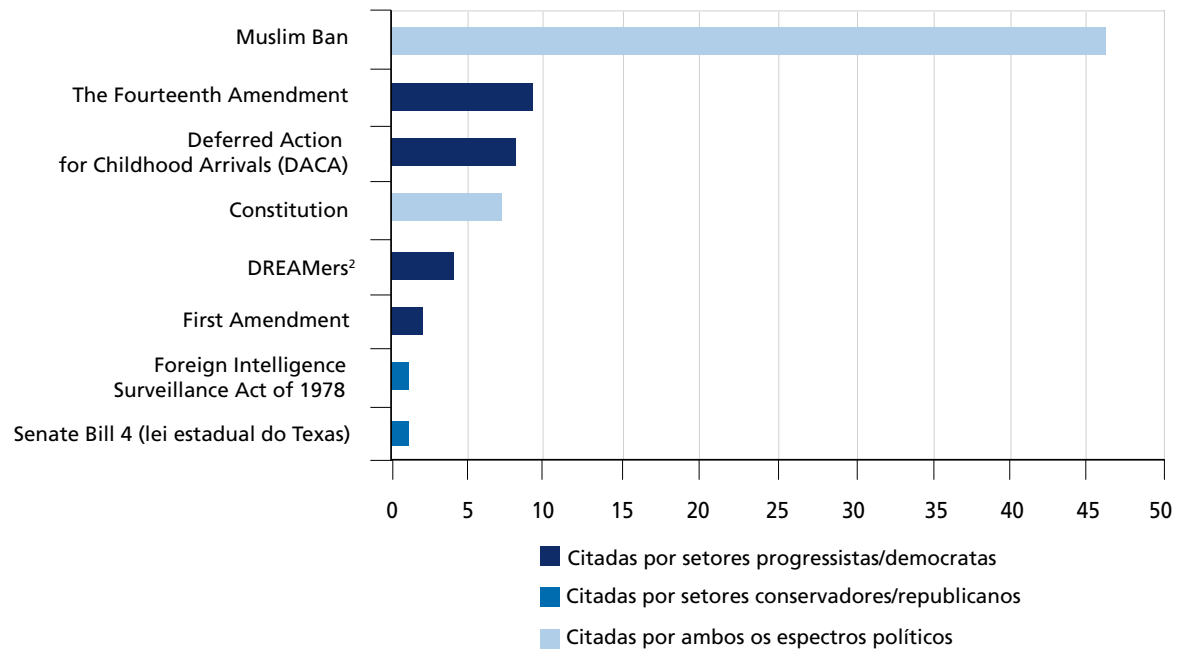

Elaboração da autora.

Notas: ${ }^{1}$ Por número de vezes que aparecem nos jornais analisados.

2 Refere-se não somente ao Development, Relief and Education for Alien Minors Act (DREAM Act), mas também às pessoas em geral que são abarcadas pelas políticas voltadas para a tolerância de imigrantes ilegais nos Estados Unidos.

19. Notícia sobre a defesa arbitrária da liberdade dos estados por Trump em King (2017).

20. Há informações de que os imigrantes eram questionados não apenas sobre crença religiosa, eram feitas também perguntas de cunho político, para saber se concordavam ou não com o governo Trump. Mais informações sobre a oposição declarada de Barack Obama em Sengupta, Haberman e Thrush (2017), Randazzo e Hong (2017), Wolfe (2017), Lazo (2017) e Meckler (2017). 
Olhando agora para as mobilizaçóes ou conflitos encabeçados por parlamentares democratas, que são os atores progressistas que mais aparecem depois das organizaçóes de direitos civis, vemos que suas atuaçóes se dão dentro e fora do Congresso americano, inclusive sobre um tema ainda não comentado, o Obamacare (ou Affordable Care Act of 2010). Eles conflitam, sobretudo, com parlamentares republicanos e com Trump sobre as possibilidades de o governo acabar com a política de saúde de Obama, defendendo fundamentos de Estado de bem-estar social para a manutenção do programa, e afirmando a importância dos direitos sociais para a garantia de direitos civis (Fins, 2017). Conflitam também com os nomeados para o Departamento de Justiça, para o Departamento de Educação e para a Suprema Corte dos Estados Unidos.

Entre as outras diversas mobilizaçōes feitas pelos democratas, podemos elencar uma série de críticas, discursos e pronunciamentos públicos a respeito do novo governo, boicote à cerimônia de posse de Trump, ${ }^{21}$ açóes judiciais e atraso no Senado para as nomeações dos seus indicados. ${ }^{22}$ As razões desses atritos se dão, geralmente, em função do passado questionável dos indicados para cargos que lidam diretamente com questóes de direitos civis. Temiam, sobretudo, uma Suprema Corte de maioria conservadora (hoje já uma realidade) que pudesse reverter ou flexibilizar decisóes históricas de direitos civis (Liptak, 2017a; Tau, Hughes e Kendall, 2017; Kendall e Tau, 2017; Shear e Liptak, 2017; Goldberg, 2017; Winkler, 2017; Bruni, 2017).

A decisão Brown v. Board of Education de 1954, por exemplo, responsável por declarar como inconstitucional a segregação racial nas escolas públicas, aparece como a mais citada em nossos materiais. Ela aparece tanto em expressóes artísticas contando a história do movimento de direitos civis quanto em argumentaçóes de parlamentares democratas contra as políticas educacionais de Betsy DeVos, que visam fortalecer as escolas autônomas (charter schools) em detrimento das públicas, além de direcionar recursos federais para escolas religiosas. Segundo os parlamentares democratas, e até mesmo alguns republicanos (como veremos), essas políticas educacionais violam leis federais de não discriminação e não seguem o que foi estabelecido pela decisão da Suprema Corte em 1954, uma vez que não consideram a realidade em que se encontram as escolas públicas e nem se apercebem da sua importância para a garantia de educação para a população negra e para a população mais pobre, podendo aprofundar a segregação racial no campo educacional.

21. Mais informações em Martin (2017b), Alcindor (2017a), Krugman (2017b), Stolberg (2017a), Weisman e Alcindor (2017), Fandos (2017), Andrews et al. (2017), Andrews (2017) e Bender e Lee (2017).

22. Para mais informaç̧ões, conferir Steinhauer e Lichtblau (2017), Shear, Fandos e Steinhauer (2017), Steinhauer e Flegenheimer (2017), Savage (2017a), Qiu (2017), Hulse (2017b) e Tau, Hughes e Kendall (2017). Informações sobre as críticas feitas aos democratas por atrasarem as confirmações dos indicados de Trump podem ser encontradas em Rove (2017), The non-silence... (2017) e Yoo e Prakash (2017). 
Outra decisão também bastante citada por parlamentares democratas e por movimentos de mulheres é a Roe v. Wade de 1973, que possibilitou a realização do aborto no país. Como veremos, essa decisão é mobilizada tanto pelos setores progressistas (parlamentares democratas e movimentos de mulheres pró-escolha), que querem protegê-la, quanto pelos setores conservadores (republicanos e movimento pró-vida), que querem revertê-la. ${ }^{23}$ As mobilizaçóes de democratas e de mulheres pró-escolha se dão sobretudo por temor de que uma nova formação na Suprema Corte reverta a decisão, em função de provocaçóes feitas pela ala conservadora. A mesma situação de temor se dá entre os liberais progressistas defensores dos direitos LGBTs, uma vez que também existe uma pressão para que os juízes da Suprema Corte revertam a decisão Obergefell v. Hodges de 2015, que permitiu o casamento homoafetivo (Liptak, 2017b). Diversos protestos e críticas foram feitos às indicaçóes de Trump para a Suprema Corte, como no caso do juiz Neil Gorsuch (Tsang, 2017; Liptak, 2017a), porém com mais intensidade contra Brett Kavanaugh, empossado em 2018.

GRÁFICO 10

\section{Expressão dos conflitos entre concepções de direitos dos liberais progressistas}

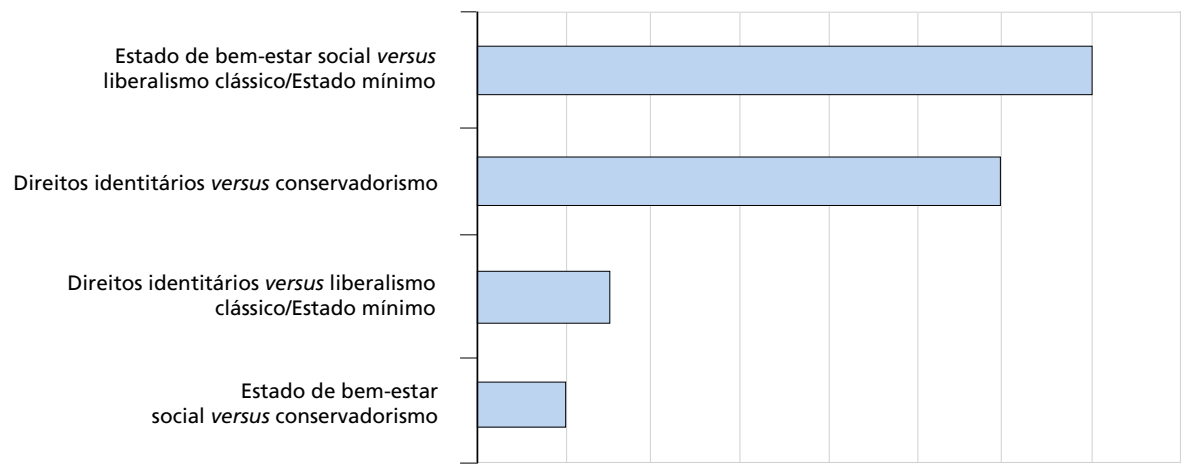

Elaboração da autora.

Se pudéssemos resumir em um quadro os conflitos entre concepçóes de direitos dos liberais progressistas e dos conservadores, teríamos uma expressão bastante clara, como já dito no início do texto, da defesa dos direitos civis a partir de concepçóes próprias de um Estado de bem-estar social e de proteção dos direitos identitários, contra concepçôes do liberalismo clássico ou próprias de um Estado mínimo.

Em um primeiro momento, as açóes dos liberais progressistas parecem, em geral, mais de negação do novo governo do que propriamente de proposição de 
medidas para evitar o avanço no desmanche de direitos conquistados a partir dos anos 1960, sobretudo com o acréscimo da defesa dos direitos identitários. Essa discussão foi levantada, inclusive, pelos próprios democratas e outros atores progressistas, que questionaram suas estratégias de atuação política, apontando erros e possíveis soluçóes. ${ }^{24}$ Aqui também entram as críticas que alguns democratas fizeram às políticas identitárias, especialmente aos movimentos das mulheres (Adelman, 2017; What..., 2017; Bellafante, 2017), o que demonstraria uma incapacidade da ala progressista de lidar com as políticas mais amplas de Trump, como as questóes referentes ao fim do Obamacare e as questóes imigratórias, levando-os a uma paralisia ou a um estado de torpor e de medo.

A impossibilidade propositiva dos democratas e progressistas no cenário de 2017, em fução da aparente ausência de alianças com setores liberais clássicos, poderá sofrer alguma modificaçáo a partir de 2019, dada a recuperação política dos democratas na Câmara dos Representantes e no Senado? E, mais importante, essa recuperação política demonstraria não a fraqueza das pautas identitárias, mas justamente o seu contrário, dado o aumento da diversidade de representaçáo política que subiu ao Congresso? Até quando terão que ficar na defensiva, evitando os desmanches de direitos?

\subsection{Liberais conservadores e o discurso liberal clássico: o movimento neocon dos direitos civis}

A ideia de que os Estados Unidos estariam vivenciando um segundo movimento de direitos civis não é algo propagado apenas entre os setores liberais progressistas, mas também entre os setores liberais clássicos e conservadores. Os fundamentos e os objetivos desse segundo movimento, contudo, são outros, diferentes dos listados e defendidos pelos progressistas. O que podemos afirmar com certeza é que se trata de um movimento de resgate de valores do passado. A questão mais complicada é saber quais são os valores resgatados especificamente. São valores eminentemente liberais clássicos, conservadores ou extremistas? ${ }^{25}$ Como já adiantamos na introdução deste trabalho, trata-se de uma combinação entre esses diferentes fundamentos, de forma que o que nos resta ao final é saber os impactos ou as consequências desse resgate para a situação dos direitos civis hoje.

Entre os atores apoiadores de Trump, os mais atuantes no cenário de 2017 são, além do próprio presidente, o Departamento de Justiça, com Jeff Sessions, o Departamento de Educação, com Betsy DeVos, parlamentares republicanos,

24. Para mais informações, ver Chira e Martin (2017), Douthat (2017), Martin e Burns (2017), Peters (2017), Williams (2017), Are... (2017) e Alcindor (2017d).

25. Quando nos referimos a valores extremistas, não queremos dizer que neonazistas estão propriamente defendendo direitos civis, mas que aparecem em protestos em conjunto com conservadores e liberais clássicos quando estes estão defendendo a liberdade de expressão, de opinião, de protestos e outros. 
alguns estados federativos e ativistas conservadores e religiosos. Como vimos anteriormente, grande parte dos conflitos estabelecidos pelos progressistas se deu em função das tentativas de Trump e de seu governo de reverter políticas de Obama numa variedade de temas e problemas. Assim, a maior parte dos conflitos encabeçados por Trump, assim como por seus apoiadores, foi justamente contra o governo anterior, procurando destruir suas políticas e também sua imagem.

\section{GRÁFICO 11}

Frases, jargões e slogans ${ }^{1}$

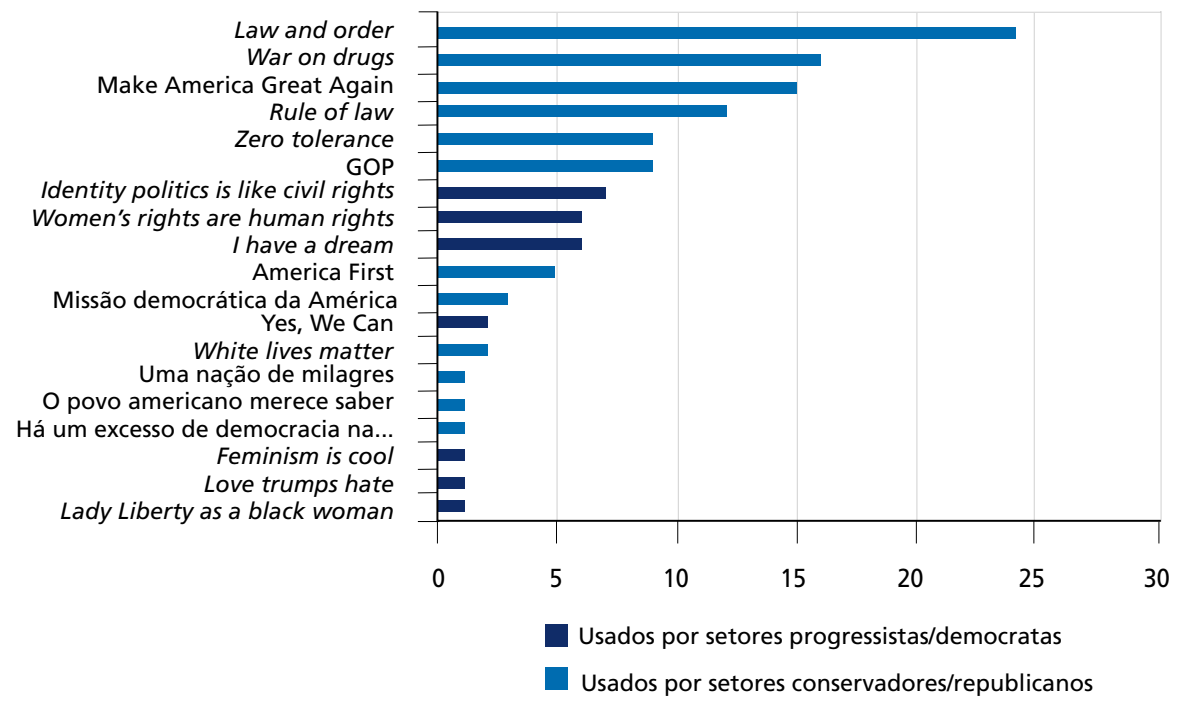

Elaboração da autora.

Nota: ${ }^{1}$ Por número de vezes que aparecem nos jornais analisados.

Obs.: GOP - Grand Old Party.

Trump, desde sua campanha eleitoral para a presidência, procurou construir um cenário de questionamento da vida pessoal e política de Barack Obama, a ponto de reforçar entre seus apoiadores indagaçóes a respeito da nacionalidade do ex-presidente, gerando polêmicas e rivalidades que cresceram, sobretudo, entre os setores mais conservadores e xenófobos dos Estados Unidos. ${ }^{26}$ Nas políticas de direitos, Trump se portou e ainda se porta como aquele que resgata os verdadeiros valores de liberdade da sociedade americana, principalmente livrando os estados federativos dos desmandos do governo federal, reforçando o valor da liberdade de expressão, de pensamento e de opinião contra o autoritarismo do "politicamente correto". Com isso, Trump e sua equipe governamental aparecem como verdadeiros reversores de políticas tidas como autoritárias, e portam-se como salvadores da

26. Mais informações em Landler (2017), Julie (2017), Anderson (2017), Thrush e Haberman (2017), Burch (2017), Alcindor (2017c) e Krugman (2017a). 
nação, ao passo que procuram resgatar a América de anos de governos progressistas que "calaram" o valor da liberdade. Os slogans de campanha de Trump, como já brevemente comentados, refletem esse sentimento e a revalorização de valores políticos clássicos e conservadores americanos.

Tomemos como exemplo as importantes questóes da violência policial e do racismo institucional, que, como já vimos, são os temas que mais emergem dos materiais analisados. Trump, juntamente com Jeff Sessions e parlamentares republicanos, declara e garante apoio aos departamentos de polícia locais e aos policiais que se recusavam a obedecer aos decretos de consentimento firmados com o governo federal anterior. ${ }^{27}$ Eles apontam, sobretudo, que essas medidas para policiar as polícias constituem-se como verdadeiros abusos de poder por parte de Obama, pois, além de interferirem em prerrogativas e liberdades estaduais, vinham causando uma sensaçáo de insegurança pública no país, dado o aumento progressivo da criminalidade, fator que Trump coloca na conta do governo de Obama. ${ }^{28}$ Em seu discurso para o Congresso, inclusive, Trump fala que a questão da segurança pública é um dos temas centrais do movimento de direitos civis dessa geração, entendendo, assim, que direitos civis se referem nada mais nada menos ao direito de ir e vir sem ser morto pela criminalidade. Desse modo, deve-se dar todo o apoio possível aos policiais e aplicar políticas de tolerância zero contra o crime e também contra as drogas. Fazer um novo movimento de direitos civis é fazer a América novamente segura para os americanos (Trump..., 2017).

Nesse tema, portanto, vemos como Trump validou seu discurso utilizando de forma arbitrária a prerrogativa dos estados para a política de segurança pública. Esta política é defendida por associaçôes policiais e cidadãos conservadores, que alegam que as políticas de Obama para a violência e o racismo policial colaboraram para a discriminaçáo e a desvalorização da atividade policial, criando o chamado blue racism (racismo contra os que usam uniforme azul, ou seja, contra policiais) (Feuer, 2017). Reforça-se aqui a necessidade de autonomia dos estados na ação de combate à criminalidade, dando o devido investimento às polícias locais, ação esta apoiada por estados e leis estaduais. O cenário mostra o argumento conservador se sustentando no discurso liberal clássico de Trump e no ativismo legal dentro dos estados para uma ação política de "criminalidade zero", consequente de uma valorização da ação policial, mesmo que isso possa colocar em risco liberdades civis de uma minoria.

27. Mais informações podem ser encontradas em Donald (2017a), Donald... (2017), Viswanatha e Reinhard (2017), Reinhard (2017), Elinson e Mahtani (2017), Elinson e Reinhard (2017), Viswanatha e Calvert (2017), Reinhard et al. (2017) e Calvert e Viswanatha (2017).

28. Para mais informações, conferir Henninger (2017), Mahtani e Barrett (2017), Riley (2017), Finley (2017), Donald (2017a), Viswanatha e Reinhard (2017) e Viswanatha e Calvert (2017). 
Outro conflito encabeçado pelo novo governo diz respeito às políticas estaduais de supressão de votos. Segundo Trump e Jeff Sessions, a Divisão de Direitos Civis do Departamento de Justiça não deveria mais, assim como nos casos de violência policial, tomar para si as investigações em torno do que os progressistas chamam de supressão dos direitos de voto das minorias (Viswanatha, 2017). Para o governo e os republicanos defensores da liberdade dos estados, o tema da administração eleitoral não deve ser da alçada do governo federal, não devendo ele, portanto, interferir nas leis estaduais eleitorais. Mas eles nada falam a respeito dos casos em que essas leis estaduais violam direitos civis básicos. Insistem no poder da administração local sobre as regras eleitorais, fazendo coro, ainda, com as acusaçóes de Trump aos democratas de terem fraudado as eleiçóes que o colocaram no poder, justamente em função da interferência federal nas políticas estaduais eleitorais (Savage, 2017b; Wines e Bosman, 2017; Liptak e Wines, 2017; Wines, 2017; Bennet et al., 2017d). De modo oculto, como já apontado anteriormente pelos progressistas, é possível ver a utilização da ideia de protagonismo político dos estados para fazer valer seus interesses na supressão de votos para os democratas, recaindo sobretudo sobre negros e descendentes de hispânicos.

Outro ponto, talvez dos mais importantes, para entender a ligação entre o liberalismo clássico e o conservadorismo, diz respeito às disputas travadas por Trump e seus apoiadores no campo da liberdade de expressão, de opinião e de pensamento. Como já exposto anteriormente, existe hoje uma batalha dentro das universidades. Trump, seus apoiadores e também alguns democratas centristas têm apoiado a ideia de que o discurso de ódio, o do racismo, o da supremacia branca, ou qualquer outro discurso discriminatório, devem ser considerados dentro da liberdade de expressão, de opiniáo e de pensamento.

Trump, Jeff Sessions, Betsy DeVos, republicanos, bem como alguns professores universitários, dão autoridade ao discurso dos supremacistas brancos ao defenderem que a liberdade de expressão é uma liberdade ilimitada, especialmente dentro de universidades, onde o pensamento deve ser livre por essência. Definem as políticas de Obama para inibir os discursos de ódio dentro das universidades como um claro uso da censura sobre o pensamento, que vai na direção contrária do que os próprios progressistas defendem (Sartwell, 2017; Berkowitz, 2017; Donald, 2017b; Steele, 2017). Para esses defensores da liberdade de expressão, existe uma diferença entre discurso de ódio e crimes de ódio, estes, sim, algo contra o que o governo deve atuar. $\mathrm{O}$ discurso enquanto discurso, isto é, o discurso enquanto não chega às vias de fato, faz parte dos valores da democracia e da liberdade americana. Se o discurso de ódio é implementado na prática, seus autores terão que enfrentar a justiça. Assim, são as açóes que devem ser punidas, não o pensamento, a expressão e o discurso. Além disso, partem do princípio de que não existe um discurso moralmente certo e um 
discurso moralmente errado, acusando os progressistas de se portarem como seres moralmente superiores (Brooks, 2017a; Steele, 2017) e de quererem impor o discurso do "politicamente correto".

Protegidos por esse escudo da liberdade clássica, supremacistas brancos que foram impedidos de palestrar em universidades passaram a denunciar o assalto à liberdade que estaria acontecendo no setor educacional como um todo. Embora não concordantes com o conteúdo da palestra, professores e até diretores de universidades se colocaram contra a censura feita aos supremacistas, alegando que a universidade deve presar sempre pela liberdade de pensamento, inclusive pela ideia do contraditório, essencial para o desenvolvimento do pensamento científico (Sartwell, 2017; Berkowitz, 2017).

Diversos atores apoiadores de Trump, entre eles Betsy DeVos (especialmente na questão da liberdade de expressão nas universidades) e Jeff Sessions (de modo mais geral), acusam os setores progressistas e identitários de promover o que querem combater, a censura e a intolerância, criando uma espécie de "Estado babá" que deve cuidar daqueles que se fazem de vítimas de racismo, machismo ou homofobia (Belkin, 2017; Donald, 2017b; Berkowitz, 2017; Sartwell, 2017). Alguns apontam, inclusive, que a vitória de Obama marcou a era ou o auge da "culpa branca" e masculina, em que homens brancos heterossexuais estariam sendo culpados de todas as mazelas da história americana, e em alguns casos tendo seus direitos legais suprimidos. O ciclo interminável de "vitimismos" diversos nas universidades teria ajudado a legitimar o discurso do politicamente correto. Para eles, as universidades estariam vivendo os impactos da gestão progressista, que teria sido uma espécie de totalitarismo brando (soft totalitarianism) (Donald, 2017b).

O uso do discurso liberal clássico para a projeção das pautas conservadoras sofreu significativos escorregóes nos episódios de Charlottesville e nas pautas de política imigratória. Em ambos os casos, Trump abriu máo do uso dessa retórica, revelando nas duas situações um descolamento ideológico em relação aos conservadores defensores do ideal liberal clássico, os chamados conservadores universalistas (conservative universalists), e também em relação a Jeff Sessions.

Em nome da civilidade e de valores americanos de universalidade, alguns republicanos (tidos como conservadores universalistas) cobraram de Trump uma fala e uma atitude mais duras com o racismo e com a intolerância no caso de Charlottesville. Não se conformavam com a ideia de que haviam apoiado um candidato que os fizesse parecer, ao final, apoiadores de supremacistas brancos. ${ }^{29}$

29. Conferir How Trump Kills the G.O.P., escrito pelo conservador David Brooks para o The New York Times (Brooks, 2017b), em que 0 autor relata o desapontamento de republicanos com relação a Trump e a sua frágil defesa de valores democráticos e antirracistas após o episódio de Charlottesville. 
Em seu primeiro pronunciamento sobre o ocorrido, Trump não repreendeu enfaticamente o crime de ódio cometido por um supremacista branco, demonstrando uma relutância em reconhecer o ocorrido como algo inaceitável (Thrush e Ruiz, 2017; Thrush, 2017; Badger, 2017a; Martin, 2017a). Ao se pronunciar sobre o atentado, que levou à morte de uma mulher, Trump disse que toda forma de ação extremista é condenável, mas acabou equiparando as manifestaçôes de movimentos negros e de organizaçóes de direitos civis (para a retirada dos monumentos confederados) com as manifestaçôes dos extremistas, esquecendo-se "apenas" de que no primeiro caso não houve morte e de que aqui o debate é sobre representatividade, simbolismo, memória e inclusão; e no segundo caso, houve morte, e o debate é sobre exclusão e fundamentos para a exclusão. Este discurso (ao menos na superfície das disputas eleitorais que os republicanos tinham em mente para o próximo ano) náo se alinha ao posicionamento republicano conservador dos universalists, o que pode ilustrar neste momento o sentimento de alguns conservadores de se autoproclamarem representantes morais dos valores liberais clássicos - e Trump, um mero artífice em alguns contextos das pautas republicanas. O que choca é a vitória moral dos supremacistas brancos, que se reconheceram no discurso do presidente e comemoraram o evento de Charlottesville (Fausset e Feuer, 2017; Black, 2017; Cotter, 2017c).

O descolamento ideológico do presidente americano do liberalismo clássico desses conservadores ganha reforço quando analisamos a relação de tensão entre as visóes de Trump e Jeff Sessions nas questóes referentes ao Muslim Ban. Trump queria limitar a entrada de imigrantes provenientes de sete países de religião muçulmana, calcado em fundamentos essencialmente conservadores do terrorismo e da segurança nacional. Aplicou inicialmente uma série de questionários de caráter político-ideológico e religioso para as pessoas que entravam no país, violando leis e liberdades clássicas americanas de respeito à diversidade e à oposição política. Jeff Sessions, durante sua sabatina no Senado, marcou posição nessa questão, declarando, naquela ocasião e em várias outras, independência com relação ao governo (Bennet et al., 2017a; Lichtblau e Apuzzo, 2017; Jeff Sessions's..., 2017; Lichtblau, 2017), dada a sua crença no governo das leis e não no governo dos homens, no Estado de direito (rule of law) e na Constituição (Jeff Sessions's..., 2017; Apuzzo, 2017). Declarou ainda que os Estados Unidos são marcados pela sua pluralidade e têm a identidade de "compaixão ao imigrante", não sendo necessários questionários sobre crença religiosa para recebê-los.

Nos casos do Obamacare e das escolas autônomas, também é possível notar o mesmo tipo de relação conflituosa entre republicanos e Trump. Os que o questionaram em função do episódio de Charlottesville são os mesmos que o questionam acerca das suas tentativas de acabar com o Obamacare (Hulse, 2017a) e de incentivar somente as escolas autônomas (Alcindor e Huetteman, 2017). 
Argumentam que a política de saúde deveria olhar com cuidado para os beneficiados do programa de Obama, para que não se cometessem injustiças com quem precisa. Da mesma forma, cobram explicaçóes de Betsy DeVos com relação ao seu plano de melhoria para escolas públicas, defendendo a sua importância e indispensabilidade para os mais pobres nos Estados Unidos, ainda que se defendam conjuntamente o avanço das escolas autônomas e o aumento dos vouchers educacionais. Além disso, também a criticam por querer destinar recursos federais para o ensino religioso cristão, demonstrando certo espanto ao vê-la dizer que trabalha para o avanço da reforma educacional no país para promover o "reino de Deus" (Goldberg, 2017).

O que parece ficar claro nessa questão do descolamento de Trump do liberalismo clássico em alguns casos específicos nem é tanto o seu conservadorismo (algo facilmente visível), mas, sim, o apoio velado de republicanos às políticas discriminatórias. Embora alguns se revoltem com o racismo aberto do episódio de Charlottesville, e embora Jeff Sessions se declare independente e fiel ao Estado de direito, para se contrapor ao Muslim Ban, essa mesma revolta náo aparece quando as políticas são veladamente discriminatórias ou revestidas de liberdades clássicas. Ou seja, o que não pode é a política explicitamente discriminatória. $\mathrm{O}$ que pode é o racismo, a xenofobia, a homofobia, o sexismo e diversas outras discriminaçóes ocorrerem de forma implícita nas liberdades de expressão, de opinião, de discurso e dos estados.

Levitsky e Ziblatt (2018), ao analisarem como as democracias morrem, apontam que isso se inicia quando os partidos, que eles chamam de guardióes da democracia, deixam entrar e crescer em seus quadros estranhos ou intrusos (outsiders) políticos perigosos às regras democráticas. Ao invés de lançarmos um olhar negativo e desconfiado sobre alguns republicanos - quando repudiam Trump por seu comportamento condescendente com supremacistas brancos -, seria possível pensarmos esses atores como os freios possíveis nesse momento para evitar o fim dos direitos, já que os progressistas se encontram isolados politicamente? Ou essa seria uma visão muito esperançosa diante do quadro de políticas discriminatórias que eles ajudam a implementar? Quais concepções de direitos possuem força suficiente para se fazerem valer na disputa política? 


\section{FIGURA 1}

Espectro das alianças e dos conflitos políticos

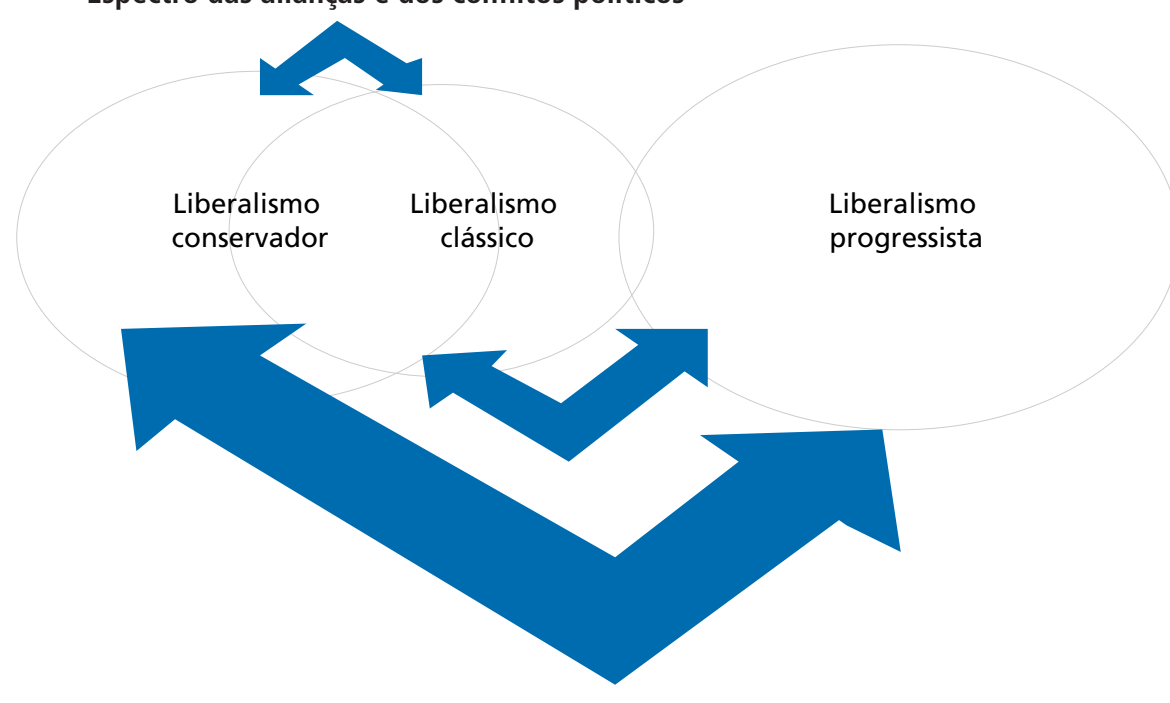

Elaboração da autora.

\section{CONCLUSÃO: ALGUMAS HIPÓTESES INTERPRETATIVAS}

Reconhecendo as limitaçóes do nosso material empírico, é importante ressalvar que tomamos as afirmaçóes feitas anteriormente como significados que foram possíveis de extrair das informaçóes dadas pelos jornais, podendo ser devidamente aprofundadas, questionadas e até negadas por estudos posteriores. A ideia aqui, contudo, é que os jornais nos trazem de alguma forma um retrato da realidade por meio das impressóes de quem os escreve, pessoas que, por sua vez, também estão inseridas no contexto sobre o qual comentam. Assim, os retratos expostos não deixam de ser uma parte significativa do que é concreto, tendo, portanto, validade de pesquisa. Dessa maneira, dizemos que não temos propriamente conclusóes, mas hipóteses interpretativas que podem ser confirmadas por estudos mais específicos sobre cada tema de direitos civis aqui tratado.

O primeiro resultado a que chegamos é o de que a defesa de direitos liberais progressistas estava, no primeiro ano do governo Trump, praticamente isolada na esfera política, ao passo que seus fundamentos e concepçóes de direitos eram rejeitados pelos outros tipos de liberalismo em cena. Assim, o que vimos durante 2017 para a defesa progressista dos direitos foi um cenário de conflitos e de pouquíssimas alianças para uma construção propositiva. As concepçóes progressistas conflitaram em diversos temas com as concepçóes liberais conservadoras e liberais clássicas, especialmente nas políticas de segurança pública, de supressão de votos e educacionais, em que os fundamentos clássicos 
fortaleceram os fundamentos conservadores. Além disso, as poucas alianças encontradas entre as concepçóes progressistas e as concepçôes liberais clássicas se deram mais no sentido de negação dos direitos identitários, argumentando que havia políticas sociais mais importantes para os democratas se preocuparem. Também encontramos alianças progressistas e liberais clássicas no repúdio aos crimes de ódio, mas que, ao mesmo tempo, defendiam o livre discurso, inclusive o de ódio nas universidades, em nome da liberdade de expressão.

GRÁFICO 12

Temas de convergência entre o liberalismo clássico e o liberalismo conservador

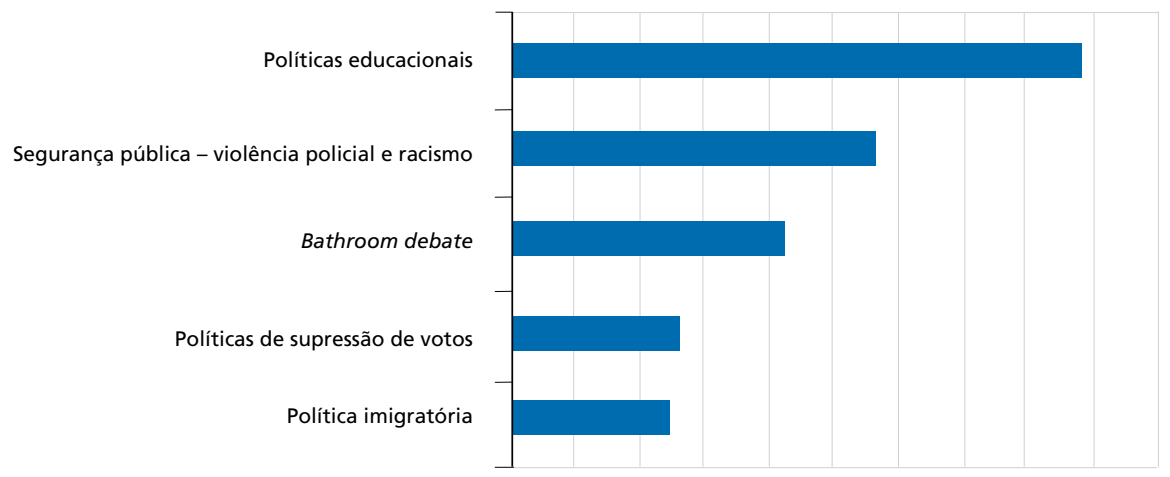

Elaboração da autora.

O segundo resultado a que chegamos é o da face conservadora do liberalismo clássico. Embora encontremos conflitos entre as concepções liberais clássicas de direitos e as concepções conservadoras, especialmente no repúdio aos crimes de ódio, as convergências entre elas chamam mais atenção, não só pela expressividade como também pelos temas em que elas causam impacto. Essa convergência mostrou-se bastante expressiva e propositiva no desmonte de políticas e de direitos progressistas. Os temas de maior convergência entre o liberalismo clássico e o liberalismo conservador foram aqueles sobre as políticas educacionais e as de segurança pública, não à toa os temas eleitos por Trump como representativos do seu novo movimento por direitos civis. Em seguida, os temas estiveram relacionados às políticas identitárias para transgêneros, às políticas de supressão de votos e à política imigratória.

Diante desses resultados, e retomando os temas comentados em nosso material, poderíamos interpretar os achados pensando na atmosfera americana de 2017 para a defesa dos direitos civis. Percebemos que o registro de argumentos apoiados no que poderíamos chamar de normas democráticas (tais como diversidade, pluralidade, tolerância religiosa, direitos humanos e igualdade) esteve bem abaixo da soma daqueles inspirados em concepçóes discriminatórias, 
envolvendo, sobretudo, racismo, xenofobia, homofobia e sexismo. Isto significa que a sociedade americana de 2017 estava falando majoritariamente sobre temas relacionados a discriminaçóes diversas, num cenário em que as formas conservadoras e liberais clássicas de defesa dos direitos civis estavam proeminentes. Fica a pergunta se a defesa progressista de direitos civis será capaz de retomar um papel propositivo na política de direitos.

\section{GRÁFICO 13}

Normas presentes na sociedade americana de 2017

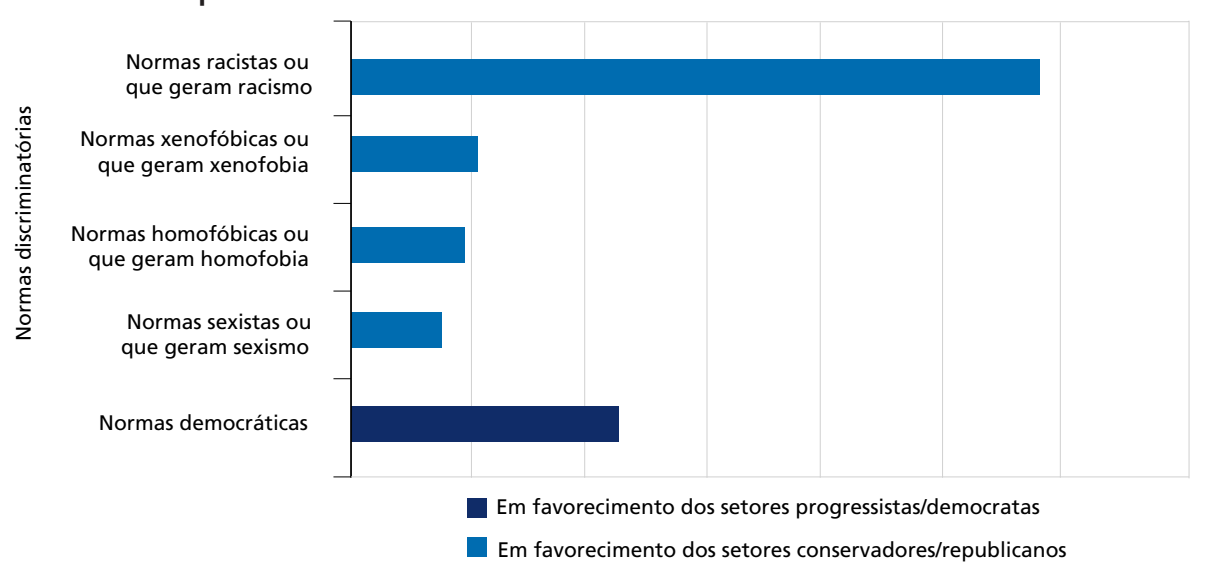

Elaboração da autora.

\section{REFERÊNCIAS}

ADELMAN, L. What the Women's March teaches us. The New York Times, 20 Jan. 2017.

ALCINDOR, Y. In Trump tweets, blacks perceive a callous rival. The New York Times, 16 Jan. 2017a.

. N.A.A.C.P., energized by liberal activists, dismisses its president. The New York Times, 20 May 2017b.

- After Charlottesville, black republicans waver in their support for Trump. The New York Times, 23 Aug. 2017c.

. Democrats search for a unified response after Charlottesville violence. The New York Times, 25 Aug. 2017d.

ALCINDOR, Y.; HUETTEMAN, E. 2 G.O.P. senators break ranks to oppose education nominee. The New York Times, 2 Feb. 2017.

ANDERSON, C. The policies of white resentment. The New York Times, 6 Aug. 2017. 
ANDREWS, N. Trump inaugural boycott expands. The Wall Street Journal, 18 Jan. 2017.

ANDREWS, N. et al. Boycott of inaugural grows: the president-elect's Twitter rebuke of a civil rights leader prompts more to join. The Wall Street Journal, 17 Jan. 2017.

APUZZO, M. A bold approach to civil rights law is likely to change definitively. The New York Times, 20 Jan. 2017.

ARE the democrats too secular? The New York Times, 2 July 2017.

AS STATUES fall, the specter of the noose rises. The New York Times, New York, 25 May 2017.

A WOMAN'S decision to give birth or abort. The New York Times, 20 May 2017.

BADGER, E. Showdown over how fringe views are defined in America. The New York Times, 22 Aug. 2017a.

. Immigrant shock: California offers hint of nation's future. The New York Times, 2 Feb. 2017b.

BAKER, A.; MUELLER, B. Records leak in garner case renews debate on police discipline and files. The New York Times, 23 Mar. 2017.

BALLHAUS, R.; REINHARD, B. President condemns anti-semitism. The Wall Street Journal, 22 Feb. 2017.

BAYLOR'S former coach denies cover-up in assault cases. The New York Times, 3 Mar. 2017.

BELKIN, D. Faculty's New Focus: Don't Offend. The Wall Street Journal, 28 Feb. 2017.

Bellafante, G. The revolution will be televised. The New York Times, 26 Feb. 2017.

BENDER, M. C.; LEE, C. E. The 45th president: Trump's Washington arrival starts clock on his agenda. The Wall Street Journal, 20 Jan. 2017.

BENNET, J. et al. Jeff Sessions smooth-talks the senate. The New York Times, 11 Jan. 2017a.

. Black lives, white lies. The New York Times, 6 Feb. $2017 \mathrm{~b}$.

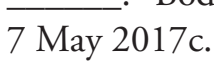

- Body cams work, if they're used right. The New York Times, . Partners in voter suppression. The New York Times, 11 Aug. 2017d. 
BERKOWITZ, P. A lawsuit accuses Yale of censoring even inoffensive ideas. The Wall Street Journal, 3 Apr. 2017.

BERMAN, A. The exclusionist. The New York Times, 18 June 2017.

BERNSTEIN, R. Let black kids just be kids. The New York Times, 26 July 2017. BLACK, R. D. White nationalist American history. The New York Times, 20 Aug. 2017.

BLINDER, A.; KOVALESKI, S. F.; GOLDMAN, A. Wave of threats at Jewish sites is raising fears. The New York Times, 1 Mar. 2017.

BOBBIO, N. A era dos direitos. Tradução de Carlos Nelson Coutinho. Rio de Janeiro: Campus, 1992.

BRANTLEY, B.; GREEN, J.; SOLOSKI, A. Too soon? Or right on cue? The New York Times, 20 Aug. 2017.

BRIGHAM, J. The constitution of interests: beyond the politics of rights. New York: New York University Press, 1997.

BROOKS, D. Getting Trump out of my brain. The New York Times, 8 Aug. 2017a.

. How Trump kills the G.O.P. The New York Times, 29 Aug. 2017 b.

BRUNI, F. The worst (and best) places to be gay in America. The New York Times, 25 Aug. 2017.

BURCH, A. D. S. Black voices on turmoil: "the world we live in". The New York Times, 17 Aug. 2017.

CALVERT, S.; VISWANATHA, A. Federal judge approves Baltimore police overhaul. The Wall Street Journal, 7 Apr. 2017.

CHIRA, S.; MARTIN, J. Marchers map out next steps. The New York Times, 23 Jan. 2017.

COTTER, H. To be black, female and fed up with the mainstream. The New York Times, 21 Apr. 2017a.

. Colors that unite and divide. The New York Times, 11 Aug. 2017b.

. Relocate statues honoring the rebels. The New York Times, 21 Aug. 2017c.

COX, K. L. Confederate monuments must fall. The New York Times, 16 Aug. 2017.

DEWAN, S.; WILLIAMS, T. A debate: should the Justice Department police the police? The New York Times, 2 Mar. 2017. 
DONALD, H. M. In Chicago, 'the Feds' are part of the problem. The Wall Street Journal, eastern edition, 26 Jan. 2017a.

. Those "snowflakes" have chilling effects even beyond the campus. The Wall Street Journal, 22 Apr. 2017b.

DONALD Trump's first 100 days. The Wall Street Journal, eastern edition, 1 Mar. 2017.

DOUTHAT, R. Who are we? The New York Times, 5 Feb. 2017.

DYSON, M. E. How black America saw him. The New York Times, 15 Jan. 2017. EGNER, J. Some mysteries have messages. The New York Times, 19 Mar. 2017. ELIGON, J.; BLINDER, A.; NAJAR, N. Drinks at a bar, ethnic insults, then gunshots. The New York Times, 25 Feb. 2017.

ELINSON, Z.; MAHTANI, S. Police decree debate rages anew. The Wall Street Journal, 11 Mar. 2017.

ELINSON, Z.; REINHARD, B. Police seek use of banned military gear. The Wall Street Journal, eastern edition, 29 Mar. 2017.

FANDOS, N. Expect pomp and a good deal of protest, too. The New York Times, 20 Jan. 2017.

FANDOS, N.; FAUSSET, R.; BLINDER, A. Confederate symbols face new resistance after violent protest. The New York Times, 17 Aug. 2017.

FAUSSET, R. Everything feels different and the same. The New York Times, 19 Aug. 2017.

FAUSSET, R.; FEUER, A. Claiming "moral victory", far-right groups blaze into national view. The New York Times, 14 Aug. 2017.

FEARING a surge of anti-semitism. The New York Times, 27 Aug. 2017.

FERNANDEZ, M. Federal judge rejects a revised voter ID law in Texas. The New York Times, 24 Aug. 2017.

FEUER, A. Two lawsuits have one aim: make city police officers' disciplinary records public. The New York Times, 1 Feb. 2017.

FINLEY, A. The weekend interview with Jim Brown: an NFL legend, Trump and America's gangs. The Wall Street Journal, 21 Jan. 2017.

FINS, J. J. The civil right we don't think about. The New York Times, 27 Aug. 2017. FLEGENHEIMER, M. et al. Seven highlights from the Gorsuch confirmation hearings. The New York Times, 22 Mar. 2017. 
FORTIN, J. F.B.I. helping American university investigate bananas found hanging from nooses. The New York Times, 3 May 2017.

FULLER, T.; FEUER, A.; KOVALESKI, S. F. A left-wing faction ready to swing its fists at the far right. The New York Times, 28 Aug. 2017.

GEIGER SMITH, E. A revisionist take on history. The New York Times, 11 June 2017.

GOLDBERG, M. The religious right's trojan horse. The New York Times, 29 Jan. 2017.

GORDON, R. Critical legal histories. Stanford Law Review, v. 36, n. 1/2, 1984.

GREEN, E. L. 2 picks for Education Dept. raise fears on civil rights. The New York Times, 5 Apr. 2017a.

. Education Dept. plans to scale back its civil rights investigations. The New York Times, 17 June 2017b.

GREEN, E. L.; STOLBERG, S. G. A review of campus rape policy after complaints by the accused. The New York Times, 13 July 2017.

GRIMES, W. Barbara Smith Conrad, singer at Center of Integration Dispute, dies at 79. The New York Times, 25 May 2017.

GRYNBAUM, M. M. "Wow": stunned cable news hosts reacted in real time to Trump. The New York Times, 16 Aug. 2017.

HAGERTY, J. R. Obituaries. The Wall Street Journal, 8 Apr. 2017.

HANNAH-JONES, N. A principal is accused of being a communist, rattling a Brooklyn school. The New York Times, 5 May 2017.

HARTOCOLLIS, A. Celebrations of diversity in distinct ceremonies. The New York Times, 3 June 2017.

HENNINGER, D. Trump and black Americans. The Wall Street Journal, 5 Jan. 2017.

HEVESI, D. William T. Coleman Jr., who broke barriers in court and cabinet, dies at 96. The New York Times, 1 Apr. 2017.

HIRSCHMAN, A. O. The rhetoric of reaction: perversity, futility, jeopardy. Cambridge: The Belknap Press of Harvard University Press, 1991.

HULSE, C. On a mission to rescue the health law. The New York Times, 5 Aug. 2017a. . Should sessions expect senatorial courtesy? Not this time. The New York Times, 13 June 2017b. 
HUNT, A. Rights and social movements: counter-hegemonic strategies. Journal of Law and Society, v. 17, n. 3, 1990.

HYMOWITZ, K. S. Women vs. feminists. The Wall Street Journal, 10 Mar. 2017.

JEFF SESSIONS'S prepared remarks at his attorney general hearing. The New York Times, 11 Jan. 2017.

JULIE, H. D. The evolution of Obama. The New York Times, 18 Jan. 2017.

KATZ, J. M. Protester arrested in toppling of confederate statue in Durham. The New York Times, 16 Aug. 2017.

KENDALL, B.; TAU, B. Court regains conservative tilt. The Wall Street Journal, 8 Apr. 2017.

KENNEDY, R. Painting of Emmett Till draws protests. The New York Times, 22 Mar. 2017.

KING, K. Fighting for migrant rights. The Wall Street Journal, 24 Feb. 2017.

KORN, M. College presidents await Donald Trump's administration. The Wall Street Journal, 8 Jan. 2017.

KRAKAUER, J.; DUNN, L. L. Don't weaken college rape policies. The New York Times, 4 Aug. 2017.

KRUGMAN, P. Fascism, American style. The New York Times, 28 Aug. 2017a. . With all due disrespect. The New York Times, 16 Jan. 2017b.

LANDLER, M. "All talk, no action", says Trump, in Twitter attack on a civil rights icon. The New York Times, 15 Jan. 2017.

LAZO, A. Immigration battle lines start to form. The Wall Street Journal, 2 Mar. 2017.

LELAND, J. Harry Belafonte knows the score. The New York Times, 5 Feb. 2017. LEVITSKY, S.; ZIBLATT, D. Como as democracias morrem. Tradução de Renato Aguiar. Rio de Janeiro: Zahar, 2018.

LICHTBLAU, E. Jeff Sessions approved as attorney general by Senate committee. The New York Times, 2 Feb. 2017.

LICHTBLAU, E.; APUZZO, M. Sessions assures senators he would rein in Trump. The New York Times, 11 Jan. 2017.

LIPTAK, A. Adding Gorsuch, a polarized Supreme Court is likely to grow even more so. The New York Times, 10 Apr. 2017a. 
. Cake case takes court back to the culture wars. The New York Times, 27 June 2017b.

LIPTAK, A.; WINES, M. Justices thwart strict voter ID law that unevenly hurt blacks. The New York Times, 16 May 2017.

LUONGO, M. T. Capturing a city at war with itself. The New York Times, 14 Aug. 2017.

MACKINNON, C. A. The first amendment: an equality reading. In: BOLLINGER, L. C.; STONE, G. R. (Ed.). The free speech century. New York: Oxford University Press, 2018. cap. 9.

MAHTANI, S.; BARRETT, J. Chicago police cited for excessive force: Justice Department calls certain practices unconstitutional, aims for consent decree. The Wall Street Journal, 14 Jan. 2017.

MANN, T. Trump turns focus to school choice. The Wall Street Journal, 4 Mar. 2017.

MARGOLICK, D. Freedom rides and film reels. The Wall Street Journal, 25 Feb. 2017.

MARTIN, J. Charlottesville raises tension of key election. The New York Times, 20 Aug. 2017a.

. When he goes low, they go... where? The left mulls how to resist Trump. The New York Times, 15 Jan. 2017b.

MARTIN, J.; BURNS, A. An alarmed base prods democrats into all-out war. The New York Times, 24 Feb. 2017.

MCCANN, M. Rights at work: pay equity reform and the politics of legal mobilization. Chicago: The University of Chicago Press, 1994.

. Causal versus constitutive explanations (or on the difficulty of being so positive). Law and Society Inquiry, v. 12, n. 2, Spring 1996.

. On legal rights consciouness: a challeging analytical tradition. In: FLEURY-STEINER, B.; NIELSEN, L. B. The new civil rigths research: a constitutive approach. Aldershot: Ashgate, 2006. p. 9-26.

MCFADDEN, R. D. John Herbers, fearless civil rights reporter, dies at 93. The New York Times, 20 Mar. 2017.

MCWHIRTER, C. Battles over confederate icons heat up: moves to eliminate symbols marking civil war's losing side meet growing resistance. The Wall Street Journal, 4 Apr. 2017. 
MECKLER, L. U.S. crafts extreme vetting methods: changes considered could require visitors to reveal passwords and cellphone contacts. The Wall Street Journal, 5 Apr. 2017.

MUSEUMS and galleries: painting blackness into western history. The New York Times, 20 Jan. 2017.

NEWMAN, A.; WANG, V. Navigating the shift to Hopper College from Calhoun College. The New York Times, 4 Sept. 2017.

PAID notice: memorials Worby, Louis L. The New York Times, 1 Feb. 2017.

PARINI, J.; CALLANAN, K. Middlebury's statement of principle. The Wall Street Journal, 7 Mar. 2017.

PAULSON, M. The musical that toppled a confederate statue. The New York Times, 21 Aug. 2017.

PÉREZ-PENAA, R. Woman linked to Emmett Till lynching says her claims were false. The New York Times, 28 Jan. 2017.

PETERS, C. My Appalachia wasn't Trump's. The New York Times, 5 Mar. 2017. POLLITT, K. March, huddle and fight: why feminism is back. The New York Times, 2 Apr. 2017.

QIU, L. Lessons and interpretations on the court nomination process. The New York Times, 4 Apr. 2017.

RANDAZZO, S.; HONG, N. Immigration case thrusts 3 judges to the forefront. The Wall Street Journal, 8 Feb. 2017.

REINHARD, B. Republican lawyer up for civil rights post. The Wall Street Journal, eastern edition, 10 Mar. 2017.

REINHARD, B. et al. Sessions shifts focus to law and order. The Wall Street Journal, 5 Apr. 2017.

RILEY, J. L. The media do battle with a pragmatic new president. The Wall Street Journal, 22 Feb. 2017.

ROBERTS, S. Bill Minor, Mississippi's chronicler of civil rights struggle, dies at 94. The New York Times, 29 Mar. 2017.

RODRÍGUEZ, J.; MARTÍnEZ, R. Gangs of L.A. The New York Times, 19 Mar. 2017.

ROMERO, S. "The lees are complex": descendants grapple with a rebel's legacy. The New York Times, 23 Aug. 2017. 
ROSENBERG, G. Positivism, interpretivism, and the study of law. Law and Social Inquiry, v. 21, n. 2, 1996.

ROVE, K. Who are the "obstructionists" again? The Wall Street Journal, 26 Jan. 2017.

RUIZ, R. R. Justice Dept. revives a policy on the seizure of assets. The New York Times, 20 July 2017.

RUIZ, R. R.; APUZZO, M. Sessions closed the Sterling case: odds are, his predecessor would have, too. The New York Times, 5 May 2017.

SANDOMIR, R. John T. Curtin, opponent of segregation, dies at 95. The New York Times, 21 Apr. 2017.

SANTOS, B. de S. Se Deus fosse um ativista de direitos humanos. São Paulo: Cortez, 2014.

SARAT, A.; KEARNS, T. R. (Ed.). The fate of law. Ann Arbor: University of Michigan Press, 1991. . (Ed.). Law's violence. Ann Arbor: University of Michigan Press, 1992. . (Ed.). Law in everyday life. Ann Arbor: University of Michigan Press, 1993.

SARTWELL, C. The "postmodern" intellectual roots of today's campus mobs. The Wall Street Journal, 25 Mar. 2017.

SAVAGE, C. Filibusters at the fore once again. The New York Times, 4 Apr. 2017a.

- Justice Dept. backs Ohio effort to purge rolls of infrequent voters. The New York Times, 9 Aug. 2017b.

. Justice Dept. seeks data from a site for dissent. The New York Times, 16 Aug. 2017c.

SAVAGE, C.; LICHTBLAU, E. Civil rights group rebukes Trump Justice Department over delay on two cases. The New York Times, 25 Jan. 2017.

SCHUESSLER, J. History and memory are not set in stone. The New York Times, 16 Aug. 2017.

SENGUPTA, S.; HABERMAN, M.; THRUSH, G. Obama speaks up, praising protests and opposing religious test. The New York Times, 31 Jan. 2017.

SHEAR, M. D. Trump arrives, set to assume power. The New York Times, 20 Jan. 2017. 
SHEAR, M. D.; ALCINDOR, Y. Finding his voice on race. The New York Times, 15 Jan. 2017.

SHEAR, M. D.; FANDOS, N.; STEINHAUER, J. Trump asks critic of vaccines to lead vaccine safety panel. The New York Times, 11 Jan. 2017.

SHEAR, M. D.; LIPTAK, A. Court selection expected soon (so is a brawl). The New York Times, 25 Jan. 2017.

SHOULD U.S. sue colleges over affirmative action? The New York Times, 4 Aug. 2017.

SILVERGLATE, H. A senator fights DeVos with fire. The Wall Street Journal, 17 Jan. 2017.

SILVERSTEIN, H. Unleashing rights: law, meaning, and the animal rights movement. Ann Arbor: The University of Michigan Press, 1996.

SMITH, R. Should art that angers remain on view? The New York Times, 28 Mar. 2017.

SOUTHALL, A. Officer faces possible dismissal over death of a Bronx teenager. The New York Times, 17 Jan. 2017.

STACK, L. F.B.I. treats shooting of 2 Indian men as hate crime. The New York Times, 1 Mar. 2017.

STEELE, S. The exhaustion of American liberalism. The Wall Street Journal, eastern edition, 6 Mar. 2017.

STEINHAUER, J. Truth or insult? Artwork in capital spawns a dispute. The New York Times, 12 Jan. 2017.

STEINHAUER, J.; FLEGENHEIMER, M. G.O.P. senators hope to speed Trump cabinet confirmations. The New York Times, 23 Jan. 2017.

STEINHAUER, J.; LICHTBLAU, E. Senate to push nominees by Trump, some unvetted. The New York Times, 8 Jan. 2017.

STEPHENS, B. The Thomas Hobbes presidency. The Wall Street Journal, 7 Feb. 2017.

STOlBERG, S. G. Accustomed to transitions, but not this. The New York Times, 18 Jan. 2017a.

. Views on abortion strain call to unite at Women's March. The New York Times, 19 Jan. $2017 b$.

. The rise and fall of federal efforts to curb police abuse. The New York Times, 10 Apr. 2017c. 
. Does a uniform keep officers in line? Baltimore thinks so. The New York Times, 15 Apr. 2017d.

. Nooses on the Fourth of July. The New York Times, 6 July 2017e.

. DeVos says Education Dept. will revisit Obama-era campus sexual assault policies. The New York Times, 14 July $2017 \mathrm{f}$.

. Hurt and angry, Charlottesville tries to regroup. The New York Times, 14 Aug. 2017g.

STOLBERG, S. G.; ROSENTHAL, B. M. White nationalist protest leads to deadly violence. The New York Times, 13 Aug. 2017.

TAU, B.; HUGHES, S.; KENDALL, B. Trump pushes senate on court pick. The Wall Street Journal, 2 Feb. 2017.

TAYLOR JUNIOR, S. How to end a campus injustice with the stroke of a pen. The Wall Street Journal, 11 Apr. 2017.

THE NON-SILENCE of Elizabeth Warren. The Wall Street Journal, 9 Feb. 2017. THE OPEN wounds of Charlottesville. The New York Times, 15 Aug. 2017.

THRUSH, G. Trump condemns racists but creates fresh uproar. The New York Times, 15 Aug. 2017.

THRUSH, G.; HABERMAN, M. Critics slam Trump's tepid condemnation of violence on "many sides" in Virginia. The New York Times, 13 Aug. 2017.

THRUSH, G.; RUIZ, R. R. A White House statement on Virginia is also found wanting. The New York Times, 14 Aug. 2017.

TRUMP supporters expect action. The Wall Street Journal, 2 Feb. 2017.

TSANG, A. Morning agenda: investing in the Trump era, a travel ban, Gorsuch nomination. The New York Times, 8 Feb. 2017.

TURKEWITZ, J. A march on history: how demonstrations have shaped America. The New York Times, 22 Jan. 2017.

VIOLENCE at Berkeley and freedom of speech. The New York Times, 4 Feb. 2017. VISWANATHA, A. Sessions is grilled by democrats: nominee for attorney general departs from some Trump positions, is pressed on race. The Wall Street Journal, 11 Jan. 2017.

VISWANATHA, A.; CALVERT, S. U.S. acts to delay police oversight. The Wall Street Journal, 4 Apr. 2017. 
VISWANATHA, A.; REINHARD, B. Probes of police will ease. The Wall Street Journal, 1 Mar. 2017.

WEISMAN, J.; ALCINDOR, Y. Former "apprentice" contestant sues Trump for defamation. The New York Times, 18 Jan. 2017.

WHAT did the women's march achieve? The New York Times, 26 Jan. 2017.

WILliAMS, D. K. The democrats' religion problem. The New York Times, 24 Jun. 2017.

WINES, M. 3 lawsuits filed against White House panel on voter fraud. The New York Times, 11 Jul. 2017.

WINES, M.; BOSMAN, J. A 'passionate' seeker of voter fraud in Kansas gets a national soapbox. The New York Times, 15 May 2017.

WINKLER, J. All the president's preachers. The New York Times, 24 Aug. 2017.

WOLFE, A. Weekend confidential: Ron Chernow - the "Hamilton" biographer is now tackling Ulysses S. Grant. The Wall Street Journal, 16 Sept. 2017.

YOO, J.; PRAKASH, S. How to stop worrying and learn to love the nuclear option. The Wall Street Journal, 7 Apr. 2017.

YOUNG, C. Rethinking campus rape police. The New York Times, 21 July 2017. ZINOMAN, J. Dropping in at the cellar. The New York Times, 29 July 2017.

BIBLIOGRAFIA COMPLEMENTAR

BOLLINGER, L. C.; STONE, G. R. (Ed.). The free speech century. New York: Oxford University Press, 2017.

GEERTZ, C. A interpretação das culturas. Rio de Janeiro: LTC, 2017. p. 107-134. SKOCPOL, T.; WILLIAMSON, V. The tea party and the remaking of republican conservatism. New York: Oxford University Press, 2016.

SOWELL, T. Civil rights: rhetoric or reality? Nova York: HarperCollins, 2009. 